Cómo citar este trabajo: Ortiz Guitart, A., \& Baylina Ferré, M. (2021). Geography and gender PhD thesis in Spain: 30 years of feminist research. Boletín de la Asociación de Geógrafos Españoles, (90). https://doi.org/10.21138/bage.3144

\title{
Tesis de geografía y género en España: 30 años de investigación feminista
}

\author{
Geography and gender PhD thesis in Spain: \\ 30 years of feminist research
}

\author{
Anna Ortiz Guitart \\ anna.ortiz@uab.cat \\ Mireia Baylina Ferré \\ mireia.baylina@uab.cat \\ Departamento de Geografía \\ Universitat Autònoma de Barcelona (España)
}

\section{Resumen}

Este artículo analiza las tesis doctorales sobre Geografía y Género presentadas en las universidades españolas en las últimas décadas. Con este análisis se pretende reflexionar sobre los intereses y preocupaciones de las autoras, ver la evolución de las investigaciones, tanto desde el punto de vista temático como metodológico, y realizar un breve balance de lo realizado hasta la fecha. A partir de una búsqueda sistematizada en distintas bases de datos de tesis doctorales de acceso libre, se han podido consultar, revisar y clasificar para ofrecer un conocimiento más global de las investigaciones doctorales en esta materia. Los resultados evidencian una evolución ascendente en el número de tesis y una mayor diversidad temática y metodológica; también destaca un desequilibrio territorial en la producción científica doctoral con perspectiva de género. Las ausencias encontradas pueden deberse, entre otras, a la carencia en formación específica de geografía y género a nivel de grado y de máster, en la falta 
de liderazgos estables en la mentoría, o en otras resistencias derivadas de entornos institucionales muy conservadores.

Palabras clave: tesis doctoral; análisis temático; análisis metodológico; perspectiva de género.

\begin{abstract}
This article analyzes the PhD dissertations on Geography and Gender that have been submitted in Spanish universities in recent decades. This research tries to reflect the interests and concerns of the authors and to study the evolution of this field of research from both a thematic as well as a methodological viewpoint. A systematized search in different databases of open access PhD theses has been carried out and the thesis have been reviewed and classified in order to offer an overview of the subject. The results show an upward evolution in the number of tesis and a diversity in new issues and methods; there is also noticeable a territorial imbalance in $\mathrm{PhD}$ production with gender perspective. The absences found may be due to the lack of specific training in geography and gender at the undergraduate and master's level, the lack of stable leadership in mentoring, and other resistances derived from conservative institutional settings, among others.
\end{abstract}

Key words: PhD dissertation; thematic analysis; methodological analysis; gender perspective.

\title{
1 Introducción
}

Este artículo analiza las tesis doctorales realizadas en España en Geografía y Género entre 1990 y 2021. Se recogen las tesis defendidas en los programas de doctorado en Geografía de las universidades españolas $y$, eventualmente, algunas tesis de género presentadas en otros programas de doctorado de disciplinas afines que cuentan con una clara perspectiva espacial ${ }^{1}$. Con este análisis pretendemos obtener un conocimiento más global de las investigaciones doctorales en esta materia, reflexionar sobre los intereses y preocupaciones de las autoras, ver la evolución de las investigaciones, tanto en las temáticas como en los enfoques metodológicos, y realizar un breve balance de lo realizado hasta la fecha.

El análisis complementa el realizado por Ortiz \& García Ramón (2016) donde se valoran los artículos publicados por geógrafas (mayoritariamente) españolas y extranjeras sobre esta

1 Se trata de una recopilación de lo encontrado por las autoras en las bases de datos oficiales y seleccionado por las mismas según su criterio. 
perspectiva en revistas de geografía españolas. La publicación en revistas académicas es quizás la forma más visible para captar la situación de la geografía del género en España; sin embargo, otros resultados, como pueden ser tesis defendidas en las universidades españolas, congresos y jornadas organizadas, proyectos de investigación financiados en convocatorias competitivas, docencia en grado y posgrado, son elementos que también pueden ayudar a valorar la situación de la geografía y el género aunque sean menos visibles y más difíciles de encontrar de forma sistemática. Este artículo pretende, pues, ampliar la visibilidad de la investigación sobre geografía y género en España, e invitar a la reflexión de jóvenes investigadoras/es y potenciales directoras/es de tesis sobre las aportaciones de esta perspectiva en los principales retos globales que se analizan en la geografía actual.

El enfoque de género en geografía aparece durante la década de los años setenta del siglo XX alentado por los movimientos feministas internacionales igual que ocurrió en otras ciencias sociales. Los primeros artículos aparecen en esta década, de la mano de autoras anglosajonas que tratan sobre temas urbanos y se publican en la revista crítica Antipode (Burnett, 1973; Hayford, 1974). En 1982, las geógrafas feministas Janice Monk y Susan Hanson afirman que las vidas de las mujeres son cualitativamente distintas de las de los hombres, y denuncian que la geografía humana, en todas sus especialidades, no haya puesto atención a esta diferencia. Las autoras identifican sesgos sexistas en la investigación geográfica y subrayan las implicaciones que ello tiene para la geografía como disciplina en su totalidad. Este inicio provoca un debate y una crítica constructiva de cómo la perspectiva feminista debe incorporarse a la geografía.

Atender a los espacios desde la especificidad de las desigualdades de género permite poner de manifiesto las experiencias de las mujeres en la diversidad de situaciones socioeconómicas y geográficas asociadas a la condición de ser mujer, lo que contribuye a la conciencia colectiva de identificar las diferencias espaciales y de género y a considerar las aportaciones teóricas del feminismo en el análisis de los procesos sociales en su manifestación espacial (lbarra \& Escamilla, 2017). A partir de aquí puede visualizarse y comprenderse cómo la geografía feminista tiene capacidad para condicionar transformaciones políticas, económicas, sociales y culturales. Los avances y la potencialidad del enfoque de género en geografía quedan reconocidos en la creación, en 1988, de la Comisión de Geografía y Género de la Unión Geográfica Internacional (UGI) (Huang et al., 2017), iniciándose un camino institucionalizado de apoyo, inclusión y diseminación de la investigación en geografía y género a nivel internacional, con impacto diferencial según los territorios. 
El género ha sido un enfoque transformador de la disciplina geográfica. Ha transformado los análisis disciplinares sobre el paisaje, el lugar y el espacio, problematizando las normatividades asociadas con las personas, las políticas y los lugares. Las geógrafas han revisado críticamente las teorías post-positivistas, más inspiradoras para sus trabajos, pero igualmente impermeables al género como el humanismo y el marxismo. Por ejemplo, considerando cómo el significado y la experiencia cotidiana son modelados por el género en la geografía humanista, o reconociendo las relaciones entre el capitalismo y el patriarcado en la búsqueda del cambio social revolucionario. Doreen Massey (1984) fue una de las primeras geógrafas que defendió que el patriarcado era clave en la formación de los procesos socioespaciales y del mismo capitalismo. El giro post-estructural en geografía desestabiliza los supuestos epistemológicos existentes y afianza el trabajo de muchas geógrafas feministas. La filosofía postmoderna proporciona a las investigadoras las herramientas conceptuales necesarias para llevar la crítica feminista a un nivel epistemológico superior. En Feminism and Geography, Rose (1993) demuestra que los argumentos acerca de la universalidad en la teoría geográfica se apoyan en un presunto productor masculino de conocimiento. Y también señala cómo los supuestos epistemológicos que separan al "investigador/a" del "investigado/a" reproducen las jerarquías y exclusiones existentes.

Indudablemente, el debate epistemológico ha ido acompañado del metodológico. La investigación desde la perspectiva de género critica la universalidad (se rechaza la idea por la cual la investigación sobre los hombres representa a toda la humanidad), pone en entredicho la objetividad como algo posible y deseable en toda investigación, y reclama un propósito emancipador, hacia un cambio social. Estos principios colocan a la metodología cualitativa como privilegiada en tanto que valora la subjetividad, lo incuantificable, complejo, único y espacialmente situado. Aunque lo que necesita la geografía feminista es una epistemología feminista crítica cualesquiera que sean sus métodos de investigación (Moss, 1995), es evidente que la proliferación de los estudios de género en geografía ha representado el punto de ignición más importante para el desarrollo generalizado de la metodología cualitativa en esta disciplina. Así pues, la geografía feminista ha contribuido a la renovación conceptual y metodológica de la disciplina, y a su vez, la geografía ha dotado la investigación feminista de la perspectiva espacial.

La selección de las tesis se ha realizado en base a una definición amplia de geografía feminista en la que el género se entiende en tanto que diferencia (roles de género), relación social (relaciones de género) y construcción social (identidades de género) (Dixon \& Jones, 2015). 
Hemos escogido las tesis que claramente utilizan la perspectiva de género en el análisis geográfico. Un criterio inicial de selección ha sido la aparición del concepto "género" en el título, resumen y/o palabras clave de la tesis. Cuando este concepto no aparece, pueden figurar otros términos como "feminista", "feminismo", "mujer", "hombre", "femenino", "masculino", "feminidad", "masculinidad" y considerar el género como categoría de análisis. En éste y otros casos, el resumen y la tesis en su globalidad sirven para validar la inclusión de la tesis en nuestro análisis o no.

Se han examinado las tesis defendidas en los programas de doctorado en Geografía o en departamentos universitarios, institutos y centros de investigación de geografía. Eventualmente se han considerado tesis de algún programa afín a la disciplina en el que tenemos constancia de tesis de género con una perspectiva espacial. ${ }^{2}$ La información se ha obtenido a partir de la consulta de las bases de datos de tesis doctorales de acceso libre TESEO (Ministerio de Educación, Cultura y Deporte), TDX (Tesis Doctorales en Red, repositorio cooperativo en formato digital de las tesis doctorales defendidas en las universidades catalanas y de otras comunidades autónomas) y DIALNET Tesis (Fundación Dialnet, Universidad de La Rioja). El período de análisis es de 1990, año de defensa de la primera tesis doctoral en geografía con perspectiva de género, hasta 2021.

A continuación se presentan las tesis analizadas atendiendo a distinto elementos considerados. Seguidamente, presentamos una descripción temática y metodológica de las tesis analizadas, y terminamos con unas conclusiones.

2 Las autoras han considerado también programas de doctorado que, aunque no pertenecientes a departamentos de Geografía, han presentado tesis que por su perspectiva teórica o su mirada geográfica pueden ser de interés para personas interesadas en la geografía y el género. Ciertamente el conocimiento de las autoras sobre esta perspectiva en geografía, la dirección de tesis que han realizado en algunas ocasiones fuera de programas de doctorado específicamente de geografía y la pertenencia al Grupo de Estudios de Geografía y Género de la UAB han ayudado a ampliar el enfoque y considerar: 1) tesis de geografía que en el título no contenían las palabras clave para este estudio ("género" y "mujeres", principalmente) pero que la perspectiva de género estaba presente de forma transversal en el contenido, y 2) tesis eminentemente geográficas de programas de doctorado más humanísticos o de otras ciencias sociales. A pesar de la rigurosidad en la hemos llevado a cabo esta investigación podría ser, sin embargo, que no hayamos considerado alguna tesis que mereciese nuestra atención para la finalidad de este artículo. Desde aquí queremos agradecer a una de las personas que ha revisado este artículo la referencia de una tesis que aunque el título no contenía ninguna de las palabras clave, el enfoque de género está presente en todo el trabajo. De esta forma, de 62 tesis que habíamos encontrado en un inicio, pasaron a ser 63. 


\section{Características de las tesis analizadas}

Desde los años 90 hasta hoy, se han defendido 63 tesis doctorales en geografía y género, repartidas en 12 universidades españolas y 24 programas de doctorado; y han sido realizadas por 59 mujeres y 4 hombres (Figura 1). La mayoría de las tesis se presentan en programas de doctorado de geografía y demografía, pero también en programas de doctorado en estudios de género, medio ambiente, arquitectura o filosofía. Las tesis presentadas en programas de doctorado que no son de geografía pero que se han tenido en cuenta para este artículo, han sido dirigidas por geógrafas y/o tienen un enfoque geográfico.

La mayoría son programas de doctorado pertenecientes a un solo departamento, pero también se encuentran otros compartidos con otras universidades (el doctorado en Estudios Migratorios, el doctorado Interuniversitario en Estudios Interdisciplinares de Género y el doctorado Interuniversitario e Interdisciplinar en Estudios de Género: Culturas, Sociedades y Políticas).

Figura 1. Universidades, programas de doctorado y número de tesis defendidas

\begin{tabular}{|c|c|c|}
\hline Universidad & Programa de doctorado & $\begin{array}{c}\text { Número de } \\
\text { mujeres/hombres }\end{array}$ \\
\hline \multirow{3}{*}{$\begin{array}{l}\text { Universidad Autónoma de } \\
\text { Barcelona (UAB) }\end{array}$} & Geografía & $21 / 3$ \\
\hline & Demografía & $11 / 1$ \\
\hline & Antropología Social & 1 \\
\hline \multirow{6}{*}{$\begin{array}{l}\text { Universidad Complutense de } \\
\text { Madrid (UCM) }\end{array}$} & $\begin{array}{c}\text { Análisis regional y paisajes } \\
\text { naturales }\end{array}$ & 1 \\
\hline & $\begin{array}{l}\text { Geografía y desarrollo: territorio, } \\
\text { sociedad y turismo }\end{array}$ & 1 \\
\hline & Geografía & 1 \\
\hline & Estudios feministas y de género & 1 \\
\hline & $\begin{array}{c}\text { Ciencias Políticas y de la } \\
\text { Administración y Relaciones } \\
\text { Internacionales }\end{array}$ & 1 \\
\hline & Economía & 1 \\
\hline \multirow[b]{2}{*}{ Universidad de Girona (UdG) } & Medio ambiente & 2 \\
\hline & $\begin{array}{c}\text { Ciencias Experimentales y } \\
\text { Sostenibilidad }\end{array}$ & 1 \\
\hline \multirow{2}{*}{$\begin{array}{l}\text { Universidad Politécnica de } \\
\text { Catalunya (UPC) }\end{array}$} & $\begin{array}{c}\text { Gestión y valoración urbana y } \\
\text { arquitectónica }\end{array}$ & 2 \\
\hline & Proyectos de arquitectura & 1 \\
\hline \multirow{2}{*}{$\begin{array}{l}\text { Universidad de Santiago de } \\
\text { Compostela (USC) }\end{array}$} & $\begin{array}{c}\text { Geografía: Análisis territorial y } \\
\text { organización del espacio en } \\
\text { Galicia }\end{array}$ & 2 \\
\hline & $\begin{array}{c}\text { Historia, Geografía e Historia del } \\
\text { Arte }\end{array}$ & 1 \\
\hline
\end{tabular}


Tabla 1. Continuación

\begin{tabular}{|c|c|c|}
\hline Universidad & Programa de doctorado & $\begin{array}{c}\text { Número de } \\
\text { mujeres/hombres }\end{array}$ \\
\hline iiEDG (interuniversitario) & $\begin{array}{c}\text { Estudios de Género: Culturas, } \\
\text { Sociedades y Políticas (promovido } \\
\text { por el Instituto Interuniversitario de } \\
\text { Estudios de Mujeres y Género } \\
\text { (iiEDG), Universidad de Barcelona, } \\
\text { Universidad Autónoma de } \\
\text { Barcelona, Universidad de Girona, } \\
\text { Universidad Rovira i Virgili y } \\
\text { Universidad de Vic-Central de } \\
\text { Catalunya }\end{array}$ & $2^{3}$ \\
\hline Universidad de Barcelona (UB) & $\begin{array}{c}\text { Geografía, Planificación Territorial y } \\
\text { Gestión Ambiental }\end{array}$ & 2 \\
\hline \multirow[b]{2}{*}{$\begin{array}{l}\text { Universidad de Zaragoza } \\
\text { (UNIZAR) }\end{array}$} & Geografía humana & 1 \\
\hline & $\begin{array}{l}\text { Relaciones de género y estudios } \\
\text { feministas }\end{array}$ & 1 \\
\hline $\begin{array}{l}\text { Universidad de Alicante (UA) } \\
\quad \text { (interuniversitario) }\end{array}$ & $\begin{array}{c}\text { Estudios Interdisciplinares de } \\
\text { Género (Universidad Autónoma de } \\
\text { Madrid, Universidad de La Laguna, } \\
\text { Universidad de Alicante, } \\
\text { Universidad de Alcalá, Universidad } \\
\text { de Las Islas Baleares, Universidad } \\
\text { de Huelva, Universidad Jaume I de } \\
\text { Castellón, Universidad Rey Juan } \\
\text { Carlos) }\end{array}$ & 1 \\
\hline Universidad de Huelva (UHU) & Género, identidad y ciudadanía & 1 \\
\hline Universidad Jaume I (UJI) & $\begin{array}{c}\text { Estudios Interdisciplinares de } \\
\text { Género }\end{array}$ & 1 \\
\hline $\begin{array}{l}\text { Universidad Pablo Olavide } \\
\text { (UPO) (interuniversitario) }\end{array}$ & $\begin{array}{c}\text { Estudios Migratorios (Universidad } \\
\text { de Granada, Universidad de Jaén y } \\
\text { Universidad Pablo de Olavide) }\end{array}$ & 1 \\
\hline $\begin{array}{l}\text { Universidad de Valladolid } \\
\text { (UVA) }\end{array}$ & $\begin{array}{c}\text { Filosofía de la cultura, de la ciencia } \\
\text { y de la sociedad }\end{array}$ & 1 \\
\hline TOTAL & $\begin{array}{c}12 \text { universidades } \\
24 \text { programas de doctorado }\end{array}$ & $\begin{array}{c}59 \text { mujeres }+ \\
4 \text { hombres }=63\end{array}$ \\
\hline
\end{tabular}

Fuente: elaboración propia a partir de los datos obtenidos en TESEO

Las tesis han seguido una evolución al alza, pasando de 6 tesis presentadas en la primera década (1990 a 1999); 17 tesis, en la siguiente (2000-2009), y más del doble, 34 tesis, en la siguiente (2010-2019). Solamente entre los años 2020 y 2021 ya se han presentado 6 tesis, la

3 Las tesis defendidas en este programa de doctorado se han presentado en la UAB. Por esta razón el número de universidades contabilizadas son 12 y no 13 como resultaría de la suma de la columna de universidades. 
misma cifra que en la primera década de estudio, y en un año marcado por la pandemia global (Figura 2).

Figura 2. Evolución de tesis defendidas

\begin{tabular}{|c|c|c|c|c|}
\hline & 1990-1999 & $2000-2009$ & $2010-2019$ & $2020-2021$ \\
\hline $\begin{array}{c}\text { Años de } \\
\text { defensa } \\
\text { por } \\
\text { universidad }\end{array}$ & $6 \cup A B$ & $\begin{array}{l}14 \text { UAB } \\
1 \text { UCM } \\
1 \text { UPC } \\
1 \text { USC }\end{array}$ & $\begin{array}{c}15 \text { UAB } \\
3 \text { UdG } \\
2 \text { UB } \\
4 \text { UCM } \\
2 \text { UNIZAR } \\
2 \text { USC } \\
1 \text { UA } \\
1 \text { UII } \\
1 \text { UHU } \\
1 \text { UPO } \\
1 \text { UPC } \\
1 \text { UVA }\end{array}$ & $\begin{array}{c}2 \text { UAB } \\
2 \text { iiEDG } \\
1 \text { UCM } \\
1 \text { UPC }\end{array}$ \\
\hline Total $=63$ & 6 & 17 & 34 & 6 \\
\hline
\end{tabular}

Fuente: elaboración propia a partir de los datos obtenidos en TESEO

En relación a la dirección y codirección de tesis, cabe destacar que más de mitad (14 tesis) han estado dirigidas por una única directora, Maria Dolors García Ramón (UAB), a la que le sigue Montserrat Solsona (UAB) (5 tesis). La figura 3 muestra como 48 de las 63 tesis, más de un $75 \%$ de ellas, han estado dirigidas o codirigidas por mujeres.

Figura 3. Dirección o codirección según género

\begin{tabular}{|c|c|c|c|c|c|}
\cline { 2 - 6 } \multicolumn{1}{c|}{} & $\begin{array}{c}\text { Única } \\
\text { directora }\end{array}$ & $\begin{array}{c}\text { Dos } \\
\text { directoras }\end{array}$ & $\begin{array}{c}\text { Único } \\
\text { director }\end{array}$ & $\begin{array}{c}\text { Dos } \\
\text { directores }\end{array}$ & $\begin{array}{c}\text { Un director y } \\
\text { una directora }\end{array}$ \\
\hline Total $=63$ & 33 & 9 & 7 & 2 & 12 \\
\hline
\end{tabular}

Fuente: elaboración propia a partir de los datos obtenidos en TESEO

Las tesis han sido escritas mayoritariamente en castellano, seguidas por el catalán, el inglés y el portugués (Figura 4).

Figura 4. Lenguas en las que se han escrito las tesis

\begin{tabular}{|c|c|c|c|c|}
\hline & Castellano & Catalán & Inglés & Portugués \\
\hline Total = 63 & 41 & 17 & 4 & 1 \\
\hline
\end{tabular}

Fuente: elaboración propia a partir de los datos obtenidos en TESEO 
Las escalas de análisis y la diversidad de lugares donde se contextualiza la investigación o se desarrolla el trabajo de campo es significativa. Países, regiones, comunidades autónomas, ciudades y barrios son las distintas escalas utilizadas, siendo la escala de país la más común en los estudios demográficos y la escala de barrio la más común para los estudios urbanos. Cabe añadir también que las comparaciones entre distintos lugares, una práctica común en nuestra disciplina, resulta ser también un ejercicio realizado por una buena parte de las tesis.

España es el país donde se han centrado más los estudios de investigación (tanto de comunidades autónomas, como de ciudades, pueblos o barrios), mientras que Europa (España, Francia, Irlanda, Polonia y Portugal) y América Latina (Brasil, Bolivia, Chile, Colombia, Ecuador, Nicaragua, México y Uruguay) son los continentes donde se concentran más países estudiados (Figura 5 y 6).

Figura 5. Mapa de los países donde se contextualizan las tesis analizadas

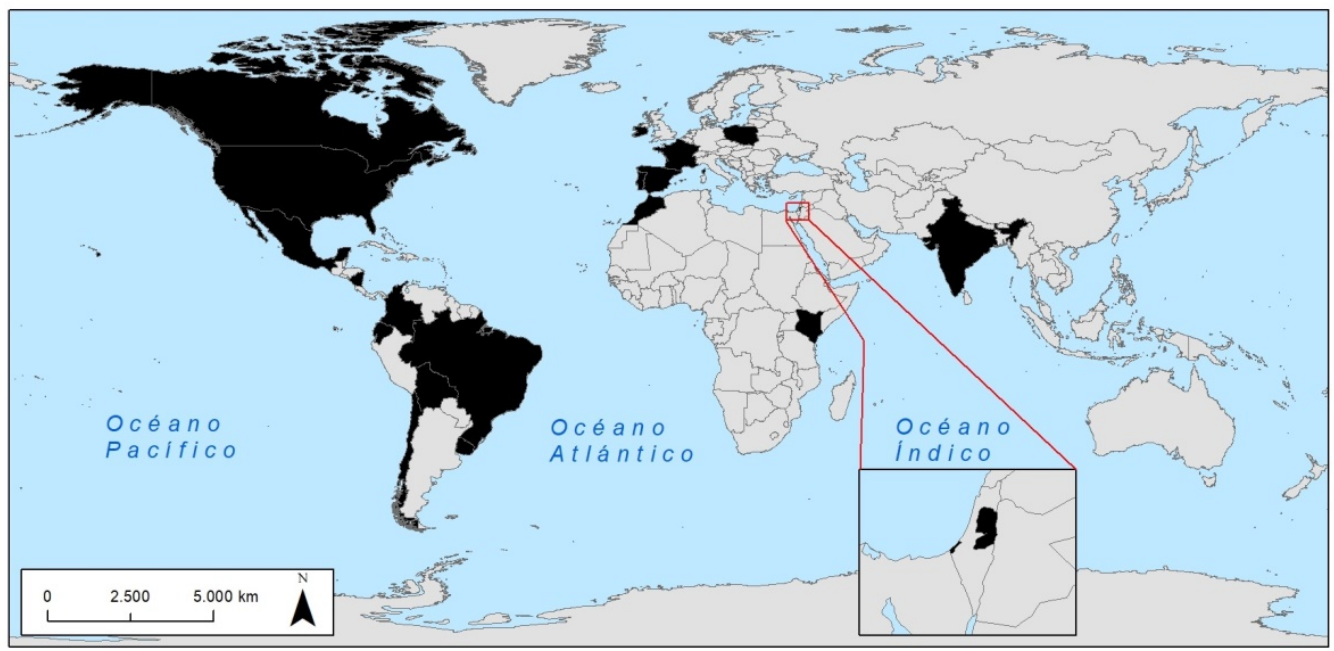

Fuente: elaboración de Meritxell Gisbert a partir de los datos obtenidos en TESEO

El origen y la procedencia latinoamericana de algunas doctorandas explica que esta región del mundo interese cada vez más como contexto de estudio, especialmente en la última década. Las doctorandas escogen a menudo sus lugares de origen por interés, proximidad y facilidad para hacer trabajo de campo, además de ser también una estrategia para ser mejor evaluada cuando solicitan becas de doctorado en sus países de origen. A diferencia de otras universidades europeas donde, por razones históricas, reciben más doctorandos de países del Sur Global y que dedican más financiación a proyectos internacionales (Lund, Berg \& Setten, 2019), en las universidades españolas la presencia de doctorandos de otras partes del mundo, exceptuando latinoamericanos, es todavía muy residual. De esta forma, en esta investigación hemos visto que 
hay muy pocas tesis centradas en países de otros continentes: en tres ocasiones aparecen países africanos (Kenia, Nigeria y Marruecos), en dos ocasiones de América del Norte (Canadá y Estados Unidos) y en dos más de Asia (India y Palestina).

Figura 6. Contextos geográficos donde se sitúan las tesis analizadas

\begin{tabular}{|c|c|c|c|}
\hline Países & $\begin{array}{c}\text { Comunidades } \\
\text { autónomas y regiones }\end{array}$ & Ciudades & $\begin{array}{l}\text { Distritos y } \\
\text { barrios }\end{array}$ \\
\hline Brasil & Bahía & $\begin{array}{c}\text { Rio Grande Pelotas } \\
\text { Recife } \\
\text { Vitória da } \\
\text { Conquista }\end{array}$ & \\
\hline Canadá & Quebec & & \\
\hline Chile & & Antofagasta & \\
\hline Colombia & & Bogotá & \\
\hline España & $\begin{array}{c}\text { Andalucía } \\
\text { Aragón } \\
\text { Asturias } \\
\text { Cataluña } \\
\text { Comunidad Valenciana } \\
\text { Galicia } \\
\text { Islas Baleares } \\
\text { Murcia } \\
\text { Navarra }\end{array}$ & $\begin{array}{c}\text { Alicante } \\
\text { Barcelona } \\
\text { Girona } \\
\text { Granollers } \\
\text { Madrid } \\
\text { Manresa } \\
\text { Mollet } \\
\text { Sabadell } \\
\text { Santa Coloma de } \\
\text { Gramenet } \\
\text { Santiago de } \\
\text { Compostela } \\
\text { Terrassa } \\
\text { Totana }\end{array}$ & $\begin{array}{c}\text { Barcelona: } \\
\text { Poblenou } \\
\text { Sarrià } \\
\text { Ciutat Vella } \\
\text { Prosperitat } \\
\text { Verdum } \\
\text { Raval } \\
\text { Sants } \\
\text { Girona: } \\
\text { Germans Sàbat } \\
\text { Taialà } \\
\text { Domeny Nord } \\
\text { Santa Eugènia } \\
\text { Can Gibert } \\
\text { Mollet: } \\
\text { Plana Lledó } \\
\text { Santa Rosa } \\
\text { Can Borrell } \\
\text { Terrassa: } \\
\text { Can Palet } \\
\text { Ca n'Anglada }\end{array}$ \\
\hline Estados Unidos & & Houston & \\
\hline Francia & Ardèche & & \\
\hline Irlanda & & Cork & \\
\hline México & $\begin{array}{c}\text { Oaxaca Tabasco } \\
\text { Yucatán } \\
\text { Guanajuato }\end{array}$ & $\begin{array}{c}\text { Ciudad de México } \\
\text { León } \\
\text { Monterrey }\end{array}$ & 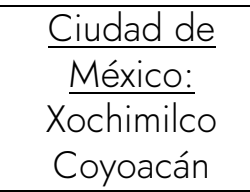 \\
\hline Polonia & & Varsovia & \\
\hline Portugal & & Braga & \\
\hline
\end{tabular}

Fuente: elaboración propia a partir de los datos obtenidos en TESEO 


\section{Análisis temático y metodológico de las tesis analizadas}

\subsection{Análisis temático}

Es difícil presentar en pocas palabras trabajos de investigación realizados en el marco de estudios de doctorado no solo por su extensión sino por la complejidad de los marcos teóricos y conceptuales, los múltiples contextos geográficos, las distintas metodologías utilizadas, el análisis exhaustivo de los resultados y las ricas conclusiones a las que llegan todas las tesis. A pesar de esta complejidad teórica y diversidad de ámbitos temáticos que a continuación se detallan, hay un aspecto que está presente en cada una de las tesis y es la importancia del lugar en la construcción del conocimiento (Monk, 1994) y de que éste es situado y refleja el contexto cultural, político y personal desde donde se hace la investigación (García Ramón \& Monk, 1994).

Las tesis han sido clasificadas según distintas temáticas de investigación, nueve en total (figura 7). En términos generales puede observarse como las tesis orientadas hacia estudios urbanos y rurales, junto con las de demografía, son las más numerosas, seguidas por las que tratan sobre migraciones, geografías de la infancia y la juventud, trabajo, medio ambiente, desarrollo y pensamiento geográfico. Se observa también como es a partir de 2010 cuando aparecen investigaciones que ponen el foco en el medio ambiente, el urbanismo feminista o las geografías de la infancia y la juventud, así como otras que introducen teóricamente las perspectivas decolonial e interseccional. Cabe decir que el desarrollo de los enfoques interseccionales en geografía feminista es previo a la consolidación del término "interseccional" y a su uso explícito en los debates académicos. Como expresa Vaiou (2018) para el contexto de los países del sur de Europa, los análisis en las intersecciones entre género, clase, lugar y cultura han sido siempre centrales en la agenda de investigación en geografía y género, desestabilizando el poder normativo de la agenda anglófona, igual de parcial y situada como la del resto, aunque posicionada como universal. 
Figura 7. Clasificación de las tesis según áreas temáticas y palabras clave

\begin{tabular}{|c|c|c|}
\hline Áreas temáticas & Palabras clave & $\begin{array}{l}\text { Número } \\
\text { de tesis }\end{array}$ \\
\hline Estudios urbanos & $\begin{array}{l}\text { Arquitectura, barrio, identidad, espacios interiores, } \\
\text { espacios públicos, literatura, movilidad, participación } \\
\text { social y política, sentimiento de pertenencia, personas } \\
\text { mayores, planificación urbana, prácticas espaciales, } \\
\text { prostitución, redes sociales, transformación urbanística, } \\
\text { urbanismo feminista, vida cotidiana }\end{array}$ & 15 \\
\hline Estudios rurales & $\begin{array}{l}\text { Agroecología, agroturismo, desarrollo local rural, } \\
\text { ecofeminismo, empoderamiento, feminización de la } \\
\text { pobreza, industria agroalimentaria, nueva ruralidad, } \\
\text { Movimiento de Mujeres Campesinas, roles y relaciones } \\
\text { de género, teletrabajo, territorio, turismo responsable } \\
\text { como movimiento social, soberanía alimentaria, turismo } \\
\text { rural, tecnologías de la información y la comunicación }\end{array}$ & 14 \\
\hline Demografía & $\begin{array}{c}\text { Análisis demográfico, desigualdades sociales, divorcio, } \\
\text { educación, hogares reconstituidos mujeres, jubilación, } \\
\text { interrupción voluntaria del embarazo, matrimonios } \\
\text { adolescentes, violencia de género, usos del tiempo, } \\
\text { trabajo, trayectorias reproductivas, trayectoria conyugal y } \\
\text { anticonceptiva }\end{array}$ & 12 \\
\hline Migraciones & $\begin{array}{c}\text { Estrategias familiares, cadenas y redes migratorias, } \\
\text { campamentos, corpolugaridades, cuerpo, geografías } \\
\text { antirracistas, migración cualificada, prostitución, proyecto } \\
\text { migratorio, transnacionalismo }\end{array}$ & 5 \\
\hline $\begin{array}{l}\text { Geografías de la } \\
\text { infancia y la juventud }\end{array}$ & $\begin{array}{c}\text { Adolescencia, feminismo, infancia, interseccionalidad, } \\
\text { juventud, ocio nocturno, movilidad, patios escolares, } \\
\text { tecnologías de la información y la comunicación }\end{array}$ & 5 \\
\hline Trabajo & $\begin{array}{c}\text { Conciliación, consumo, comercio callejero, } \\
\text { discriminación, empresarias, emprendedoras, industria } \\
\text { textil, invisibilización, trabajo reproductivo, trabajo } \\
\text { informal y precario }\end{array}$ & 4 \\
\hline Medio ambiente & $\begin{array}{l}\text { Contaminación, cultura, mujeres indígenas, } \\
\text { ecofeminismo, ecología humana, filosofía de la cultura, } \\
\text { gobernabilidad ambiental, mareas negras, pescadoras, } \\
\text { soberanía alimentaria }\end{array}$ & 3 \\
\hline Desarrollo & $\begin{array}{c}\text { Asociaciones, cooperación, desarrollo sostenible, } \\
\text { espacio territorial, indicadores de bienestar, políticas } \\
\text { públicas }\end{array}$ & 3 \\
\hline $\begin{array}{l}\text { Pensamiento } \\
\text { geográfico }\end{array}$ & $\begin{array}{c}\text { Academia, colonialismo, educación superior, literatura } \\
\text { de viajes, imaginario colonial, viaje }\end{array}$ & 2 \\
\hline TOTAL & & 63 \\
\hline
\end{tabular}

Fuente: elaboración propia a partir de los datos obtenidos en TESEO

A continuación se exponen cada uno de los ámbitos de investigación. 


\section{a) Espacios urbanos}

Las tesis presentadas en el ámbito de los estudios urbanos son las más numerosas, quince en total. Este hecho no resulta extraño si consideramos que su estudio ha interesado significativamente a las geógrafas feministas ya que en ellos pueden analizarse las relaciones entre las identidades de género y la construcción del espacio. Las personas, dependiendo de su género, edad, etnia, cultura, religión, clase social y capacidades físicas, se identifican con los espacios y los experimentan de forma diferente. Los espacios públicos juegan un papel diferencial en la configuración de la vida cotidiana de hombres y mujeres y en la forma como sus vivencias elaboran el sentido cultural del espacio. Cuatro tesis realizadas en ciudades catalanas centran su interés en las implicaciones de las rehabilitaciones y construcciones de diversos espacios públicos en distintas ciudades y en su impacto sobre la calidad de vida de la ciudadanía, enfatizando el papel de las mujeres en los movimientos sociales y vecinales, así como en la construcción del sentido de pertenencia (Ortiz, 2004; Cucurella, 2009; Díaz, 2009; Serra, 2019) ${ }^{4}$.

Partiendo también de la idea de que el espacio no es neutral, que su uso está relacionado con el poder económico, cultural y social y que hombres y mujeres lo han ocupado de forma muy distinta a lo largo de la historia, Cevedio (2003) ${ }^{5}$ reflexiona sobre la concepción androcéntrica dominante en la historia de la arquitectura occidental y reivindica la cultura de la diferencia para romper con las estructuras jerárquicas que el sistema capitalista y patriarcal mantiene entre géneros y espacios exteriores; mientras que Nomdedeu (2017) analiza los espacios interiores desde una perspectiva de género. Desde el urbanismo feminista, Cioccoletto (2014) y Valdivia (2021) aseguran que en la práctica urbanística contemporánea se ha generalizado la visión de la vida cotidiana desde una concepción exclusivamente productiva minusvalorando las actividades relacionadas con el cuidado y la reproducción de la vida. Por tanto, la ciudad reproduce unas jerarquías y unas desigualdades de género que se manifiestan no solo en los espacios sino en el uso del tiempo, como señala también una de las primeras la tesis en el ámbito de los estudios urbanos (Prats, 1997).

4 Las tesis analizadas se detallan en el Anexo (nombre y apellidos, título de la tesis, año de defensa, programa de doctorado y universidad).

5 En algunas ocasiones no se han encontrado las tesis completas en las bases de datos consultadas y se han buscado artículos o libros de las autoras relacionados con sus trabajos doctorales para poder revisar su contenido. 
La necesidad de integrar la perspectiva de género en la planificación urbana puede extenderse también a las políticas y estrategias de transporte, como señala Maciejewska (2020). Esta investigadora analiza los patrones de movilidad diferenciados por género teniendo en cuenta además factores como la edad, la presencia de niños/as en el hogar, la disponibilidad de vehículo privado y la situación económica de mujeres y hombres.

Centrándose en mujeres mayores, Coelho (2013) analiza cómo éstas se relacionan con su entorno urbano más cotidiano y llega a la conclusión de que la ciudad brasileña Vitória da Conquista no ofrece una buena calidad de vida para su población mayor porque no tiene buena accesibilidad a los espacios físicos y sociales, y ambientalmente no es una ciudad demasiado saludable. Por su parte, Pérez-Rincón (2014), en Ciudad de México y Barcelona, y Cedro (2016) en Recife, toman como eje central de su investigación el análisis de las prácticas cotidianas de mujeres residentes en barrios desfavorecidos que, con sus luchas y resistencias, reivindican el derecho a la vivienda, las infraestructuras cotidianas y los servicios sociales. También Pallarés (2019) sitúa su investigación en Ciudad de México y estudia como mujeres que ejercen la prostitución en la calle se apropian del espacio público y cómo esta apropiación les permite empoderarse, crear redes de apoyo mutuo y construir las bases para la formación de una nueva identidad.

Finalmente, y desde un enfoque más humanístico, histórico y literario, pero acercándose a todos las temáticas señaladas en este apartado, Edo (2005) analiza novelas de escritoras del siglo XX y capta las percepciones y experiencias que tienen las mujeres en el entorno urbano donde viven, tanto en espacios privados como públicos, así como la movilidad que tienen en la ciudad.

\section{b) Espacios rurales}

Durante mucho tiempo, esta línea temática fue la más importante en la geografía del género en España en consonancia con la tradición ruralista de la geografía española (García Ramon \& Nogué, 1984). En este ámbito se desarrollan fundamentalmente dos líneas de investigación, referidas al trabajo de las mujeres en el ámbito rural: la contribución laboral de las mujeres en las explotaciones agrarias familiares y el papel que desempeñan en la diversificación económica de las zonas rurales. Las catorce tesis situadas en este ámbito contribuyen al debate teórico en torno a la división entre el trabajo productivo y reproductivo y muestran como cualquier intento de explicar el trabajo de las mujeres en este contexto necesita considerar el control patriarcal del proceso de trabajo y la propiedad de los medios de producción. Asimismo, aportan ideas significativas sobre la construcción cultural de la masculinidad y la feminidad en el contexto rural 
en diferentes regiones españolas, así como el papel de las mujeres en el proceso de reestructuración rural y la importancia de tenerlo en cuenta para el diseño de políticas rurales por parte de la administración.

Las primeras tesis doctorales en este ámbito fueron presentadas a principios de los años 90 de la mano de Cànoves (1990) y Salamaña (1991), la primera y segunda tesis de geografía y género presentadas en España, centradas en el estudio del papel de las mujeres en las explotaciones familiares agrarias en Cataluña. Años más tarde, se defienden las tesis de Baylina (1996) sobre el trabajo informal que realizan las mujeres a domicilio en áreas rurales de España en el marco de la internacionalización de la producción, la flexibilización del trabajo y la reestructuracion económica de estos espacios; la de Caballé (1998) sobre el trabajo de las mujeres en el agroturismo y Sparrer (2005) en el turismo rural, la de Morales (2002) sobre la participación de las mujeres en la industria agroalimentaria en áreas rurales, y la de Blanco (2005) sobre el teletrabajo llevado a cabo por mujeres que viven en áreas rurales de Cataluña, Ardèche y Québec.

Relacionada también con las oportunidades que ofrecen las tecnologías de la información y la comunicación para mujeres y jóvenes universitarios que viven y trabajan en áreas rurales y periféricas, Pose (2012) estudia la relación entre género y tecnología y muestra las desigualdades de género todavía existentes en el ámbito tecnológico.

En el contexto latinoamericano, siguiendo también con la idea de adaptación a los cambios sociales y territoriales en el medio rural, Ayllón (2003) introduce la idea de 'territorialidad de la familia' y se centra en el estudio de las familias y en las estrategias que ponen en marcha sus miembros para permanecer en un territorio empobrecido y con altas tasas de emigración.

Los estudios rurales más recientes se acercan al análisis de las áreas rurales actuales, postproductivistas y multifuncionales, e incorporan nuevos temas y enfoques para entender su heterogeneidad. Dos trabajos se centran en el papel que juegan mujeres emprendedoras en el desarrollo local de áreas de montaña de Cataluña (Pallarés-Blanch, 2014) y en el desarrollo del turismo rural en Aragón (Hervás, 2016). También Moreno (2018) se centra en el turismo pero esta vez en Nicaragua, planteándose de qué manera el turismo orienta su desarrollo a la igualdad de género y al empoderamiento de las mujeres. Las conclusiones no son nada halagüeñas ya que continúan dándose situaciones de explotación sexual de mujeres, niños y niñas, y de precariedad en el empleo femenino en el sector turístico. Por tanto, a pesar de que 
el turismo se proyecta teniendo como objetivo la reducción de la pobreza, no se logra reducir ni ésta, ni la desigualdad de género.

Las relaciones sociales ligadas al trabajo y la relación de las mujeres con la naturaleza aparecen como dos de los ejes temáticos transversales en geografía rural y género. Según Baylina \& Salamaña (2006) el primero es básico para dar visibilidad y reconocimiento a la pluriactividad de las mujeres y el segundo utiliza la relación de las mujeres con el medioambiente para denunciar la situación de dominio de la sociedad patriarcal. De la misma forma, conceptos como la identidad, la sexualidad, el poder, la representación social o la construcción sociocultural de la ruralidad permiten comprender la diversidad de lo rural. De esta forma, tesis presentadas más recientemente, como las de Pinheiro (2018) y Dorrego (2018), coinciden en visibilizar la situación de discriminación que viven las mujeres en el mundo campesino, pero también el compromiso que tienen por una agricultura ecológica y una alimentación saludable. Pinheiro (2018) observa como las mujeres rurales trabajan conjuntamente para crear mecanismos de participación política con el objetivo de combatir las desigualdades de género en el medio rural, proponiendo la soberanía alimentaria y la producción agroecológica como elementos de un proceso de transformación local y global. Dorrego (2018), por su parte, comparte con la investigación anterior la preocupación por la soberanía alimentaria y la agricultura local y ecológica, y considera que bajo estos principios las mujeres campesinas e indígenas de Bolivia pueden construir un modelo de producción, comercialización y alimentación basado en los principios de igualdad de género y satisfacer, así, las necesidades básicas de las personas.

\section{c) Demografía}

Las doce tesis presentadas en el ámbito de la demografía se centran en una gran variedad de aspectos demográficos - desde los matrimonios, las separaciones, la fecundidad, la ocupación, la jubilación, entre otros- y captan los cambios sociales a lo largo del tiempo y en distintos contextos geográficos. La primera tesis en este ámbito es la de la demógrafa Montserrat Solsona (1991). La autora realizó un análisis demográfico y territorial de la actividad femenina en España en las décadas de los setenta y ochenta, y observó, entre otros aspectos, una disminución de la actividad laboral entre las mujeres más jóvenes debido a la mayor duración de los estudios, un retraso en la edad del matrimonio y un incremento de la actividad laboral femenina. También se refiere a una geografía de la actividad femenina caracterizada por una mayor actividad económica de las mujeres casadas en regiones económicamente más dinámicas y una menor actividad en las regiones con una tasa de desempleo masculina más alta. No será hasta casi dos 
décadas más tarde cuando aparece nuevamente una tesis sobre la ocupación femenina, en este caso, centrada en la inserción laboral de las mujeres migrantes en el mercado de trabajo español (Vidal, 2009). Esta investigación muestra una complementariedad sociodemográfica en función del origen y una segmentación de la estructura ocupacional femenina en función del lugar de nacimiento. Así, mientras las mujeres españolas tienen tasas de actividad alta y posiciones cualificadas, las mujeres migrantes ocupan lugares de trabajo como empleadas domésticas y en la restauración, independientemente de su nivel formativo.

Entre las dos tesis anteriores, se presenta la de Ortega (2002) que analiza desde una perspectiva de género de qué forma se representan los cambios demográficos de los años noventa (emancipación de los/as jóvenes, formación y ruptura de uniones y familias, maternidad y paternidad, métodos anticonceptivos, aborto, salud sexual y reproductiva y sexualidad) en dos telenovelas catalanas.

Posteriormente, centrándose en la fecundidad desde ópticas y contextos latinoamericanos distintos encontramos las tesis de Paredes (2003) y Medina (2005). La primera se centra en el estudio de la maternidad y la paternidad en un contexto de cambio en las relaciones de género y en las dinámicas familiares en Uruguay; mientras que la segunda analiza la transición de la fecundidad, la nupcialidad y la anticoncepción en Colombia. También Chager (2014) se centra en la nupcialidad y la maternidad, comparando la situación en tres países (India, Kenia y Colombia) y observa como al aumentar los niveles de escolaridad femenina, la edad del matrimonio se retrasa.

Un tema nuevo aparece en la tesis de Ferrer (2012), sobre la incidencia del aborto en España durante la década de 1998-2008. La autora señala, entre otros aspectos, que las mujeres menores de 30 años son las que presentan las tasas de aborto más altas, y que estas tasas, junto con unas tasas de fecundidad bajas, indican que el aborto voluntario es un complemento para retardar, limitar o espaciar la maternidad, pero en ningún caso resulta ser un método substitutorio a la anticoncepción.

Desde una mirada de género, Cuevas (2020) y Ruiz Vallejo (2018) estudian las uniones y las separaciones. La primera analiza la entrada a las primeras uniones en México y el segundo las separaciones conyugales en Colombia. Mientras que el tránsito a la primera unión es uno de los elementos que marcan el paso de la juventud a la edad adulta y representa un punto de partida para la etapa de formación familiar, las separaciones conyugales son un elemento central de los sistemas de nupcialidad, y una variable fundamental para entender las tasas de fecundidad de un 
país. Entre otros aspectos, Cuevas (2020) muestra que la entrada en unión de las mujeres tiene relación con la trayectoria laboral y la residencia posterior a la unión. De esta forma, muestra, por un lado, como en una sociedad donde las relaciones de género son menos equitativas, las mujeres que logran alcanzar un mejor estatus en el mercado laboral tienden a aplazar la entrada en unión y, por otro, que existe un patrón de entrada en unión en México muy particular ya que el hecho de compartir el lugar de residencia con padres y/o suegros juega un papel fundamental al inicio de la formación familiar. Por su parte, Ruiz Vallejo (2018) contribuye al conocimiento sociodemográfico de la separación conyugal en Colombia. Muestra como las separaciones conyugales expresan cambios tanto en las relaciones de género -uno de ellos sería la cada vez mayor participación de las mujeres en el espacio público-, como en las transformaciones de los valores asociados con la vida de pareja y la reproducción. También García (2018) se centra en los hogares post-divorcio (reconstituidos o monoparentales), pero esta vez para estudiar la distribución en el uso del tiempo de las actividades productivas y reproductivas en estos hogares.

El problema de la violencia de género lo aborda Gómez (2018). Y es imprescindible hacerlo cuando Naciones Unidas confirma que esta violencia es el mayor impedimento para alcanzar la igualdad de género. La autora se centra en la violencia de género letal y no letal física y sexual en Europa; y en la mutilación genital femenina y el matrimonio forzado que se da en edades tempranas en España.

En este mismo año, Domínguez (2018) analiza las características de la jubilación en España y las desigualdades sociales en el envejecimiento y en el acceso a la pensión de jubilación. La autora revela que el género, la educación y la salud generan desigualdades que se acumulan a lo largo de la vida laboral y se manifiestan en el momento de la jubilación, evidenciando la necesidad de luchar contra las desigualdades sociales que se dan tanto en el proceso de envejecimiento como en el acceso a la pensión de jubilación.

\section{d) Migraciones}

En las últimas décadas, al analizar las trayectorias de hombres y mujeres migrantes se han empezado a considerar otras dimensiones, más allá de las oportunidades del mercado laboral o la mejora del estatus económico: la resistencia a la opresión socioeconómica y de género, el deseo de experimentar nuevos ambientes o la expresión libre de la sexualidad. Más aún, las personas tienen distintas respuestas emocionales hacia la movilidad, y éstas están significativamente influenciadas por las condiciones socio-económicas, políticas y culturales de la 
migración. Cada vez más, en los estudios sobre migraciones y con el fin de entender las complejidades sociales, económicas, políticas y experienciales de la movilidad humana y el sentido de pertenencia, se han empezado a considerar cuestiones relacionadas con las emociones (Ortiz, 2018).

De acuerdo con estas consideraciones, cinco de las tesis con perspectiva de género presentadas en España se acercan al estudio de las migraciones tomando en consideración, entre otros aspectos, las emociones de las personas que migran. La primera es la de Pedone (2003) que analiza las cadenas y redes migratorias de familias ecuatorianas en España, sus trayectorias socioespaciales, las prácticas cotidianas y las relaciones de género para mostrar de qué forma construyen espacios sociales transnacionales; sin olvidarse en señalar el coste emocional que tiene para las mujeres (sobre todo para las que son madres) el proceso migratorio. Por su parte, Carrasco (2011) estudia los cambios identitarios de género y culturales que viven las mujeres marroquíes migrantes en Andalucía, influenciados por la clase social, la etnia o la edad. La autora concluye que los cambios no destruyen las desigualdades de género, étnicas o de origen nacional preexistentes, ni en quienes migran ni en la sociedad de acogida. En otro contexto y desde una perspectiva interseccional, Salvatori (2018) estudia la movilidad de mujeres mexicanas cualificadas que cruzan la frontera para insertarse en el mercado laboral norteamericano en empleos no calificados.

Desde una geografía feminista, antirracista e histórica, Delicado (2017) analiza la prostitución forzosa de mujeres nigerianas que realizan servicios sexuales en la periferia de Alicante y los procesos de deshumanización y racialización que sufren por las desiguales relaciones de poder en el mundo globalizado. La autora expone las causas históricas y actuales que explican la presencia de mujeres víctimas de trata, procedentes del Delta del Níger. La feminización de la pobreza, el empobrecimiento estructural, los conflictos armados y la corrupción explican la expulsión de estas mujeres.

En la misma línea pero incorporando un enfoque descolonial, Méndez (2021) indaga sobre los procesos de territorialidad y sentidos de lugar en las narrativas de mujeres sudamericanas que habitan en campamentos de la ciudad chilena de Antofagasta. Incorpora la noción de corpolugaridades como propuesta analítico-política para la acción feminista antirracista y como una herramienta para develar las formas en las que se ha ido construyendo la otredad y los discursos neocoloniales y de racialización.

e) Infancia y juventud 
Las geografías de la infancia y la juventud han permitido visibilizar las vidas cotidianas de los niños y niñas, adolescentes y personas jóvenes, sus experiencias y prácticas espaciales en los lugares donde viven; captar sus deseos y necesidades y estudiar como construyen sus identidades y sus sentimientos de pertenencia en el lugar. La experiencia de la infancia y la juventud no es universal, sino una construcción social y, por esta razón, no son categorías fijas ni estáticas, sino más bien procesos flexibles y ambiguos. Cinco tesis se enmarcan en esta categoría mostrando unos resultados que se comprenden contextualizados en sus espacios geográficos y culturales.

Las dos tesis centradas en niños y niñas de primaria son las de Castela (2015) y Saldaña (2021), centradas en la movilidad cotidiana y en los patios escolares, respectivamente. Castela (2015) estudia la movilidad hogar-escuela de niños y niñas en una ciudad catalana, Granollers, teniendo en cuenta el género, la edad de los niños/as y la procedencia de los progenitores para estudiar el transporte utilizado, la autonomía y la percepción del entorno urbano de niños y niñas y de sus progenitores. Uno de sus resultados muestra que los más pequeños perciben las calles con mucho tráfico como negativas pero, al mismo tiempo, disfrutan de los desplazamientos gracias a los espacios de juego que encuentran a lo largo de sus recorridos habituales por el barrio. Saldaña (2021), por su parte, estudia los patios escolares, uno de los lugares de la escuela donde más se visibilizan las desigualdades en el acceso, el uso y el disfrute de los espacios en función del género. Según sus observaciones en distintos patios escolares de Santa Coloma de Gramenet, las niñas ocupan los espacios menos valorados y las ubicaciones periféricas en el patio, realizan actividades estáticas y ocupan poco espacio, mientras que los niños se ubican en los espacios centrales y mejor equipados y ocupan gran parte del espacio del patio desarrollando actividades expansivas (deportivas, en su mayoría) y de mucho movimiento. La tesis propone estrategias de transformación para los patios, que comprenden cambios físicos y de gestión.

Las experiencias y prácticas cotidianas de jóvenes y adolescentes son estudiadas por las tres investigaciones que se presentan a continuación. Todas ellas tienen en común la atención que recibe el estudio de las emociones experimentadas por estos chicos y chicas y la pluralidad de significados que ayudan a comprender qué representa ser joven en distintos contextos geográficos.

La primera de ellas es la de Rodó (2014) que muestra, desde una perspectiva feminista e interseccional, cómo el acceso de las personas jóvenes al espacio público está determinado por 
las diversas estructuras de poder como el género, la sexualidad, la etnia o la clase social; y como estas personas experimentan en distintos espacios cotidianos -como la casa, el lugar de trabajo, los espacios públicos, los lugares de ocio, entre otros-, experiencias de opresión y privilegio, así como de bienestar y malestar según sus identidades. Observa, en una ciudad catalana, Manresa, como la heteronormatividad, el miedo en la calle y el control de la comunidad, que tienen que ver con los ejes identitarios mencionados, son factores determinantes para experimentar del acceso al espacio público de las personas jóvenes. También desde una perspectiva interseccional, pero esta vez en el ámbito rural mexicano, Solana (2015) analiza las experiencias espaciales y cotidianas de mujeres jóvenes focalizando la atención en la transición hacia la adultez y tomando en consideración aspectos como la escolarización, la emancipación, el trabajo en el hogar y fuera de él, así como el tiempo libre.

Centrándose en la noche, una parte del día muy poco estudiada, y en la adolescencia, una franja de la vida muy olvidada en los estudios urbanos de nuestro país, Mecca (2018) estudia las primeras experiencias de ocio nocturno de los chicos y chicas adolescentes teniendo en cuenta la experiencia en el espacio público en Barcelona, la emancipación de la familia, la exploración de la identidad, el desarrollo de competencias sociales y espaciales en la ciudad y el barrio donde se vive, y la construcción de redes de amistades.

f) Trabajo

Las cuatro tesis enmarcadas en esta temática ponen de relieve que el trabajo es un elemento fundamental en el estudio de las relaciones de género. Todas ellas muestran la invisibilización del trabajo reproductivo de las mujeres, las desigualdades de género observadas en el trabajo productivo y las estrategias que siguen las mujeres para llevar a cabo la conciliación entre trabajo y familia. Desde una perspectiva antropológica, Domínguez (2005) estudia todos estos aspectos a partir de una mirada histórica al trabajo femenino en la industria textil de Sabadell en el siglo $X X$.

El trabajo informal de las mujeres en Brasil y México es objeto de análisis en las tesis de Veleda da Silva (2003) y Mojica (2014), respectivamente. En ellas, se analiza la relación entre el lugar, el trabajo precario e informal y las relaciones familiares, sociales y laborales, así como la configuración de nuevas identidades a partir de la ocupación de los espacios públicos. Por un lado, Veleda da Silva (2003) estudia el comercio callejero desde la geografía cultural para captar la relación entre el lugar y su significado, así como los discursos y las prácticas espaciales que producen los camelôs (trabajadoras y trabajadores informales) en el espacio público; 
mientras que Mojica (2014) estudia las diferencias de género, edad y clase que se dan en torno al uso del espacio y del tiempo de la población en sus labores cotidianas. Su investigación reconoce los lugares y trabajos invisibles que realizan las mujeres como base de la reproducción social en un entorno patriarcal y la importancia que tienen las redes familiares de apoyo como núcleo central proveedor de cuidados. Con algunos elementos de análisis comunes a estos trabajos mencionados, la tesis de Añover (2014) analiza el papel de las mujeres emprendedoras en el desarrollo sociolaboral de Aragón visibilizando las dificultades que tienen para hacer frente a los estereotipos asociados a la división de género, la segregación horizontal y la desigualdad de género en los usos del tiempo.

\section{g) Medio ambiente}

Gobernabilidad ambiental, feminismo ambientalista y ecofeminismo, son algunas de los conceptos y líneas de investigación que siguen las tres tesis de geografía y género presentadas en España en el marco de los estudios medioambientales. La primera, de Agüera (2010), muestra de qué forma el género modela las relaciones de poder en un contexto de participación pública, concretamente en la organización de tres plataformas ciudadanas que hacen frente a conflictos ambientales y territoriales en Cataluña. Si tradicionalmente los espacios de poder se muestran generizados, siendo los hombres los que lideran las actividades y representan a la organización y las mujeres las que desarrollan actividades de apoyo y tienen una menor visibilización, en este trabajo se muestra como las relaciones de poder, como toda construcción social, no son fijas y pueden ser transformadas.

Desde la perspectiva del feminismo ambientalista - definido como la relación entre mujeres y naturaleza observada a través de su realidad material y de la forma específica en la que las mujeres interaccionan con la naturaleza, especialmente en comunidades rurales y pesqueras-, Braga de Melo (2017) analiza la contaminación provocada por mareas negras, a partir del estudio de caso de las mariscadoras (pescadoras artesanales que trabajan en la recolección de mariscos y crustáceos, y que tienen la pesca como su profesión habitual y su principal forma de vida) afectadas por el accidente del barco petrolero Prestige en la costa gallega. Los resultados muestran que en el periodo previo al accidente, el área costera ya estaba fragilizada por la contaminación y la falta de medidas de protección ambiental, y que las mariscadoras ocupaban una posición marginal dentro del sector pesquero, a pesar de su papel como administradoras ambientales, inversionistas en la economía local, conservacionistas de la cultura marisquera y activistas sociales. 
En América Latina, Tapia (2018) sitúa su trabajo dentro del ecofeminismo, la corriente feminista que estudia los vínculos entre la discriminación hacia las mujeres y la destrucción de la naturaleza. El ecofeminismo cuestiona la pretendida universalidad de la filosofía occidental y reivindica principios propios de la epistemología indígena, como son el reconocimiento de sujetos no humanos, el respeto a la Tierra, la complementariedad y la intersubjetividad. En su trabajo combina el análisis teórico con los testimonios de mujeres indígenas y campesinas en defensa de los territorios ante proyectos extractivistas y las estrategias que ponen en juego estas mujeres para desestructurar los estereotipos sexistas que las oprimen.

\section{h) Desarrollo}

El desarrollo local y el desarrollo sostenible centran la atención de tres tesis presentadas en los años de estudio. La de De Reymaeker (2014) analiza proyectos de cooperación sobre desarrollo y género realizados entre Cataluña o Andalucía y el norte de Marruecos y propone un instrumento metodológico para estudiar intervenciones de cooperación al desarrollo teniendo presente el papel del espacio (pensado, practicado e interpretado). Las dos siguientes se centran en identificar formas de asociación y actividades productivas para conseguir un desarrollo sostenible en dos contextos geográficos distintos, uno situado en América Latina, la comunidad indígena del Pueblo Kichwa en la Amazonía ecuatoriana (Veloz, 2019), y el otro en Palestina (Hajjaj, 2020). La primera investigación analiza el espacio territorial indígena teniendo en cuenta sus condicionantes geográficos, recursos naturales y tenencia del suelo comunitario, para pasar a estudiar la participación de las mujeres en el desarrollo local y terminar destacando la necesidad de priorizar la integridad cultural y territorial, la relación armónica con el medio ambiente y el respeto de los derechos de los pueblos y personas indígenas. Desde una conceptualización más de políticas públicas, la investigación situada en Palestina reflexiona sobre el desarrollo sostenible, el bienestar y la calidad de vida a partir de un análisis de género del presupuesto público y de las acciones gubernamentales.

\section{i) Pensamiento geográfico}

En este ámbito encontramos dos tesis muy distintas que, sin embargo, giran en torno a la construcción del conocimiento geográfico. Una lo hace desde una visión histórica y literaria (Cerarols, 2008), y la otra desde un análisis de la academia y la geografía (Pujol, 2011).

La tesis de Cerarols (2008) profundiza en las vinculaciones existentes entre el viaje y la práctica imperial, así como en sus implicaciones en la constitución de nuevos conocimientos geográficos. Concretamente, analiza narrativas de viajes de hombres y mujeres desde una perspectiva crítica 
y de género para captar la construcción de las geografías imaginarias españolas de Marruecos durante el periodo colonial. La representación que estos relatos hacen de las mujeres de Marruecos se convierte en el ejemplo más claro para captar de qué forma se construye la alteridad cultural (eurocéntrica, imperialista y machista) y se enfatiza la vulnerabilidad para justificar y legitimar el colonialismo español en Marruecos.

La tesis de Pujol (2011), por su parte, analiza la persistencia de las desigualdades de género dentro de la academia y corrobora que a pesar de las políticas de igualdad iniciadas desde hace ya unos años en universidades de todo el mundo, las carreras universitarias continúan dominadas por hombres y marcadas por una fuerte competitividad y jerarquización, hecho que no ayuda en ningún caso a la consecución de una igualdad de oportunidades para hombres y mujeres.

\subsection{Análisis metodológico}

La mayor parte de las autoras reflexionan ampliamente sobre los procedimientos que seguirán en su investigación y se refieren a las críticas que las investigadoras feministas han planteado desde hace décadas a las formas de investigar de las instituciones académicas. De ellas destacan el carácter androcéntrico y sexista de la investigación, la invisibilidad y desatención a las experiencias e intereses de las mujeres, la desvalorización de los saberes asociados a lo femenino y las desigualdades de género en los procesos de producción del conocimiento.

La mayoría de las investigadoras doctorales $(74,1 \%)$ utilizan exclusivamente la metodología cualitativa; un 11,2\% emplean únicamente la metodología cuantitativa; y un 14,5\% basan su análisis en métodos mixtos.

Las tesis que se apoyan solamente en métodos cuantitativos (7 tesis) son todas del programa de doctorado en Demografía y las que utilizan métodos mixtos (9 tesis) corresponden a programas de doctorado en Geografía (6 tesis) y en programas de Demografía (3 tesis). Las tesis que analizan aspectos demográficos utilizan bases de datos de los censos de población, padrones, registros, encuestas de distintos temas elaborados por las instituciones públicas y privadas nacionales e internacionales. Con ellos tratan estadísticamente la información.

La investigación con métodos mixtos es hoy un enfoque metodológico aceptado y una tendencia creciente en ciencias sociales, aunque no dominante (Fielding, 2008). Esta tendencia también se observa en las tesis aquí examinadas. Se trata de acercarse al fenómeno social que se pretende investigar desde distintas perspectivas utilizando distintos métodos; un ejercicio que requiere más trabajo y sobre todo un dominio de más y diversas técnicas metodológicas por parte del 
investigador/a. Uno de los argumentos que aportan las investigadoras que combinan ambos métodos es la complejidad creciente de los fenómenos sociales y el hecho por el cual es en la interacción (triangulación) dónde se obtienen mayores avances analíticos. La combinación de métodos más habitual en las nueve tesis que utilizan ambas metodologías es la del análisis de datos estadísticos y el uso de alguna técnica cualitativa como entrevistas, grupos de discusión o el análisis biográfico (historia de vida). Braga de Melo (2017) necesita recoger datos estadísticos y de recursos pesqueros sobre Galicia y revisar el marco regulador sobre el transporte de hidrocarburos y la protección de las zonas de costa para analizar el impacto de la marea negra en las mariscadoras gallegas y su rol en la recuperación del territorio, a quienes entrevista en profundidad. Otra combinación frecuente es la de la realización de encuestas propias y entrevistas. Ayllón (2018), se apoya en cuestionarios elaborados ad hoc para hacer su propia auditoría sobre el presupuesto familiar en su estudio sobre la territorialidad de la familia en un medio rural de fuerte migración. La autora necesita precisión sobre este dato y el uso de otra técnica le permite confrontar los resultados obtenidos a partir de las entrevistas.

En dos tesis las investigadoras despliegan múltiples técnicas cuantitativas y cualitativas, manifestando una riqueza y complejidad metodológicas notable (Pallarès-Blanch, 2014; Veloz, 2020). Entre ellas, técnicas para medir la desigualdad y representarla gráficamente como el coeficiente de Gini y la curva de Lorenz; el análisis del territorio con el uso de los Sistemas de Información Geográfica (SIG) y las herramientas adicionales para el cruce de datos cartográficos; análisis estadísticos; entrevistas; observaciones participantes y no participantes; y encuestas. La multiperspectiva metodológica ha encontrado en los mapas y en los SIG un lugar importante desde el cual abrir un nuevo espacio epistemológico capaz de combinar métodos considerados tradicionalmente como cuantitativos (estadística, cartografía, SIG) con la interpretación de las historias personales, el análisis del discurso o los métodos participativos (Font-Casaseca, 2020). Además de la utilización crítica de análisis espaciales complejos en un sentido cuantitativo con esta técnica, los SIG pueden utilizar datos cualitativos (textos, imágenes, audios) para ser representados gráficamente (Kwan, 2002; Pavlovskaya, 2009) y permiten realizar una reflexión profunda sobre cómo entender lo cualitativo en un contexto digital.

La metodología cualitativa es la teoría de análisis más utilizada por las investigadoras doctorales. Bajo esta teoría, la investigación se basa en la producción de datos descriptivos para proceder a su interpretación: las propias palabras de las personas, habladas o escritas, y la conducta observable. Más que un conjunto de técnicas se trata de un modo de encarar el mundo empírico (Taylor \& Bodgan, 1992). De modo sintético, los caracteres identificadores de esta 
teoría son los siguientes: 1) la investigación procede de forma inductiva, es decir, las investigadoras e investigadores desarrollan conceptos, explicaciones, partiendo de las pautas de los datos y no recogiéndolos para evaluar modelos, hipótesis o teorías preconcebidas; 2) el investigador/a ve el escenario y las personas que investiga en una perspectiva holística, interesa su pasado y su situación actual; 3) los investigadores/as son sensibles a los efectos que ellos/as mismos causan a las personas que son objeto de su estudio; 4) no se busca la "verdad" sino la autenticidad, el objetivo es obtener un conocimiento auténtico de las experiencias de las personas; 5) se da un especial énfasis a la validez en la investigación; 6) los métodos cualitativos destacan el aspecto humano de la vida social, se acepta el error en el juicio humano (Baylina, 1997). Las primeras tesis defendidas en geografía y género no tuvieron otra opción para responder a su objetivo. Cánoves (1990) y Salamaña (1991), en sus investigaciones sobre el trabajo de las mujeres en las explotaciones agrarias familiares en Cataluña, exploraron las estadísticas oficiales para valorar la participación profesional de las mujeres en el trabajo agroganadero. La ausencia de datos, la terminología estadística inapropiada para calificar la actividad profesional o la consideración del trabajo doméstico y de cuidado como no trabajo, obligaron a las investigadoras a recurrir a los métodos cualitativos para conocer la realidad. Esta ausencia de registros oficiales para contabilizar el trabajo de las mujeres también fue evidente en el trabajo en la economía sumergida, donde las mujeres estaban sobrerrepresentadas e invisibilizadas (Baylina 1996).

La investigación desde la perspectiva de género ha criticado la universalidad; aboga por una investigación de las experiencias de las mujeres y las relaciones de poder entre mujeres y hombres; y pone en entredicho la objetividad como algo posible y deseable en toda investigación. Hay un posicionamiento por parte de la investigadora y la persona investigada estableciéndose una relación intersubjetiva que forma parte del mismo análisis; y tiene un propósito emancipador. Esta investigación comprometida con un cambio social exige una reflexión por parte de quien investiga acerca de su impacto en el proceso de investigación. Cada vez más investigadoras tienen en consideración cómo su localización (social, política, económica, cultural, religiosa...) y posicionalidad forman parte del mismo proceso de producción del conocimiento y de evaluación de los resultados. Su reflexividad puede contribuir a una investigación más rigurosa. La empatía radical y el hecho de analizar y procesar muy conscientemente los datos pueden aumentar la relevancia política y social de la investigación (Sultana, 2017), que es lo que la geografía feminista pretende. Hajjaj (2020), en su tesis sobre el bienestar y la calidad de vida de las mujeres en Palestina a partir de un enfoque de 
promoción de derechos y participativa, es muy consciente de las complejas localizaciones de las mujeres y de ella misma como investigadora. Como expresa, "el proyecto no solo busca respuestas a mis preguntas de investigación, sino que pretende lograr un cambio y una mejora en el bienestar de las participantes en el trabajo de campo, a quienes considero uno de los grupos más marginados de mi comunidad" (p. 50). Por lo tanto, la reflexividad puede ir más allá de una medida correctiva en el proceso de investigación.

Las emociones, pues, son un aspecto inevitable y necesario en la realización de toda investigación, cualquiera que sea el marco epistemológico de partida (Bondi, 2005). En la investigación que conlleva interacciones con otras personas con las cuales se co-construye la información, los/as investigadores/as entran en relaciones interpersonales que generan ricas dinámicas emocionales. Consciente de los discursos de apropiación y extractivismo, Leyla Méndez (2021) enfatiza, en su tesis sobre mujeres migrantes que habitan en macrocampamentos en Chile, el deseo de articular una práctica descolonial en su investigación. Como expresa, el trabajo de campo "fue un proceso complejo y doloroso en el que pude reflexionar sobre las asimetrías dentro de las investigaciones, así como respecto a los procesos de reciprocidad no mercantilizada" (p. 170). Méndez utilizó la interpelación, la recepción de preguntas o la autointerrogación para poner en juego la consciencia crítica y la emergencia de procesos de descolonización del pensamiento y la acción. De este proceso también surgió un nuevo método de participación, un taller de creación poética.

Entre los métodos cualitativos, es la entrevista en todas sus variantes el más utilizado (48 investigadoras, un 77,4\% del total). De hecho, persiste como la mejor forma para capturar la realidad social en geografía humana (Dowling et al., 2016), y se ha asociado a las geografías culturales, urbanas y feministas (Bosco, 2017), donde el objetivo, particularmente en éstas últimas, es dar voz a los sujetos de la investigación. Las formas de instrumentalizar la conversación son distintas según el alcance (individual o en grupo), el grado de estructuración (cerrada, semiestructurada o abierta) o la profundidad de sus contenidos o desarrollo (focalizada o holista -historia de vida-). La terminología que utilizan las autoras es variada, pero a partir de la combinación de las características mencionadas, las investigadoras utilizan sobre todo la entrevista individual en profundidad (56\%), la entrevista individual semiestructurada (48\%), la entrevista en grupo (grupo focal) (12,5\%), la entrevista individual holista (historia de vida) $(10,4 \%)$ y la entrevista abierta $(6,2 \%)$. 
La entrevista en profundidad responde a una investigación teóricamente motivada que busca ilustrar cómo las personas dan sentido a sus propias experiencias. Las personas son entrevistadas con relación a un fenómeno concreto y la entrevista se centra en la percepción subjetiva de este fenómeno. A partir del análisis previo del fenómeno y de algunas hipótesis, el investigador/a elabora el guion de entrevista. Esta técnica es útil para la mayoría de los temas tratados en las tesis y resulta la forma principal de recolección de datos en bastantes de ellas, en particular si se abordan temas complejos y controvertidos que marcan la experiencia individual (Carrasco, 2011; Ferrer, 2012). La entrevista individual semiestructurada es también muy utilizada cuando se desea seguir un guion predeterminado, aunque se deja margen al descubrimiento, con espacio para seguir trayectorias temáticas a medida que se desarrolla la investigación. Es una técnica de uso frecuente también para interrogar a personas expertas en relación con el tema que se investiga. Por su parte, el grupo de discusión permite obtener información de un grupo de personas en base al discurso fluido por la propia interacción entre los/as participantes. La persona moderadora no interviene excepto para mantener la discusión dentro del tema de estudio. Como técnica flexible que permite analizar muchos temas y obtener muchas ideas con respecto al comportamiento del grupo ante una situación o fenómeno, es también bastante utilizado por las investigadoras (Domínguez, 2005; Díaz, 2009). El grupo de discusión tiene potencial como estrategia de empoderamiento para las participantes ya que facilita desafíos a las creencias dominantes y da un espacio para la discusión y la reflexividad sobre temas de género. En ocasiones las entrevistas van acompañadas por notas o diarios de campo. Un 8\% de las investigadoras así lo explicitan en sus investigaciones. Por lo observado, las autoras sienten la necesidad de dejar constancia de información de contexto durante el proceso de realización de las entrevistas, aunque después es difícil determinar cómo se integran en los datos y se utilizan analíticamente.

Una tercera parte de las investigadoras (35,4\%) manifiestan realizar observaciones directas del fenómeno de estudio. Algunas recogen datos de forma sistematizada en un marco espaciotemporal delimitado y son una muy buena fuente de información para ciertos temas. Ortiz (2004) utiliza la observación sistemática para recoger datos sobre el uso y la apropiación de los espacios públicos en Barcelona. Con los mapas resultantes puede determinar la frecuencia y la forma en que se utilizan estos espacios, así como las características de los grupos sociales que participan de ellos. La información obtenida es imprescindible para completar su investigación con otros métodos. En un caso, la investigadora realiza una investigación participante de dos años con la comunidad indígena de su estudio, integrándose e implicándose 
en la vida cotidiana del grupo (Veloz, 2020). Con la participación de la autora en el fenómeno que observa (las formas de supervivencia de una comunidad agrícola empobrecida) comprende las situaciones que producen dicho fenómeno.

Con el tiempo, estos métodos más utilizados se han enriquecido con técnicas que los suplementan. En general, movilizan otros sentidos y formas de representación más allá de la textual. Algunos ejemplos señalados por las investigadoras son los paseos participativos, que implican caminar con los/as sujetos de investigación mientras se les pregunta a fin de capturar actitudes, emociones y conocimientos acerca del entorno (Mecca, 2018), los mapas participativos (Cedro, 2016; Solana, 2018), y los métodos visuales, como la elicitación de fotos (De Reymaecker, 2014; Castela, 2015), los dibujos, el uso del vídeo (Mecca, 2018), la televisión (Ortega, 2002), u otros medios de comunicación a fin de capturar visualmente la vida social y complementar con lo que no se dice, aquello que se expresa verbalmente o por escrito. Al margen de todos estos, algunas investigadoras también utilizan la literatura, las escritoras como informantes (Cerarols, 2002; Edo, 2005).

Dos tesis destacan por la diversidad de métodos utilizados, que puede explicarse, como mínimo, por el volumen y la variedad de personas informantes. Para analizar la construcción del sentido de pertenencia en la ciudad de Girona desde un análisis intergeneracional, interseccional y de género, Serra (2019) despliega ocho técnicas para llegar a grupos muy distintos de informantes: cartas y dibujos utilizados con niños/as, asambleas y blogs de opinión para trabajar con jóvenes, o grupos de memoria para conversar con personas mayores, entre otros. Saldaña (2020) tiene como objeto de estudio proponer una transformación de los patios escolares, que concibe como lugares educativos de primer orden. La autora utiliza la metodología de Investigación-Acción-Participativa, entendida como un continuo de participaciones, colaboraciones, acciones y conocimientos co-producidos con los/as participantes (Askins, 2018), ya que a su juicio es la más adecuada de acuerdo con las pedagogías críticas y feministas. Es la comunidad educativa de su estudio quien define sus propios problemas y quien busca las soluciones con sus propios recursos y los de su entorno.

Hay investigadoras que crean nuevos métodos de investigación, validan herramientas metodológicas para cuestiones concretas o aportan conocimiento al debate metodológico. Ortega (2002) propone una metodología para analizar el contenido cualitativo de las telenovelas desde una perspectiva demográfica y de género. Rodó (2014) crea un instrumento metodológico y de análisis (Mapas Relieve de la Experiencia) para recoger datos sobre la 
interseccionalidad de identidades. Este método relaciona tres dimensiones, la social, psicológica y geográfica para mostrar cómo las categorías de diferenciación se constituyen mutuamente, se experimentan de forma simultánea y cómo el lugar es un factor esencial para la acentuación o atenuación de la experiencia de malestar y bienestar. También con la interseccionalidad como vehículo para analizar la migración invisibilizada de las mujeres cualificadas de México a Estados Unidos, Sara Salvatori (2018) crea la herramienta metodológica Transgrama, que pone en relación los sistemas de estratificación conformados por el género, la clase y la etnia/raza, con los estudios transnacionales. Es decir, poniendo en juego los varios contextos sociopolíticos que conforman la geografía de la movilidad de los sujetos e incluyendo también el análisis de las relaciones (redes) que coadyuvan la movilidad de las migrantes.

En las tesis de Cioccoletto (2014) y Gómez (2018), la metodología está en el objetivo central de la investigación. Adriana Cioccoletto pretende validar una metodología de análisis para evaluar el urbanismo a escala de barrio, basada en la aplicación de la experiencia cotidiana. La propuesta incluye aplicar indicadores urbanos con datos primarios extraídos con técnicas cualitativas. Por su parte, Gómez analiza críticamente las fuentes de datos e indicadores que se utilizan para abordar la violencia de género a escala europea. La tesis invita a reflexionar sobre el impacto de las formas de medición en las conclusiones que se extraen sobre la magnitud y la dinámica de la violencia de género.

Casi la mitad de las tesis examinadas (46,7\%) abordan explícitamente experiencias de las mujeres. Para muchas feministas estudiar a las mujeres fue una decisión política, una estrategia para hacerlas visibles, para desenmascarar la anterior exclusión del centro de la investigación geográfica con la idea de evolucionar con la inclusión de los hombres en las muestras para conocer legítimamente la posición relativa de las mujeres (McDowell, 2000). Sin embargo, todavía hoy es muy importante seguir con este cometido y no debemos verlo como una etapa a superar. Dorrego (2018) en su tesis sobre las mujeres en los sistemas de producción agroecológica en Bolivia, pone en el centro los saberes de las campesinas en las actividades agrícolas y con su voz señala la discriminación de las mujeres en el mundo rural al no ser consideradas ni actoras económicas, ni productoras de conocimiento ni sujetos sociopolíticos. En general, las investigadoras utilizan la experiencia como autoridad analítica desde una posición crítica, constructiva y vivencial. A partir de ahí, surgen fenómenos que resultan problemáticos desde la perspectiva de las mujeres que quizás no lo son desde la de los hombres y se investigan. Como señala Harding (1987), no existe problema alguno si no hay una persona (o 
grupo de personas) que lo defina como tal y lo padezca: un problema es siempre problema para alguien.

Esto no excluye que la investigación feminista haya ampliado sus enfoques y no se centre únicamente en las mujeres, incluyendo la construcción social de la feminidad y la masculinidad y los estudios de la construcción y el mantenimiento de las múltiples identidades de género en distintos lugares, circunstancias y escalas geográficas. Asimismo, las mujeres estamos insertas en relaciones desiguales de poder y el género no puede separarse de la clase, la raza, la edad, la orientación sexual, la diversidad funcional, la nacionalidad, la religión, etc. Más de la mitad de las tesis $(56,4 \%)$ incorporan explícitamente otra categoría de diferenciación además del género. En concreto, 19 tesis consideran la edad, 16 la clase social, 8 la etnicidad/raza, 6 la sexualidad, 6 la nacionalidad, 1 la diversidad funcional y 1 la ciudadanía. Así pues, las combinaciones género y edad, y género y clase social aparecen como las más frecuentes en tanto que configuradoras de desigualdad o discriminación. Finalmente, seis de las tesis examinadas $(9,6 \%)$ manifiestan utilizar un análisis interseccional; es decir, parten de un marco teórico que considera un conjunto más amplio de opresiones y privilegios y las relaciones entre ellos.

\section{Conclusiones}

La investigación doctoral en geografía y género ha mostrado una evolución muy positiva en España a lo largo de treinta y un años. La diseminación de los enfoques constructivistas sociales y la importancia de los discursos consolidan, en la última década, la investigación en geografía feminista, a pesar de que el giro cultural no esté en el mainstream de la geografía española.

Las conclusiones de las tesis representan un avance para la geografía evidenciando la dificultad y el sesgo que supone hoy analizar problemáticas socioespaciales sin considerar las dinámicas desiguales que introducen el género y otras categorías de diferenciación. Temas tan actuales como las migraciones transnacionales, el cambio climático, la despoblación de los espacios rurales, las desigualdades sociales y urbanas, la crisis económica y de cuidados, o el impacto de la pandemia global, no pueden explicarse sin considerar el género, entre otras categorías, en sus causas y consecuencias. A la variedad temática de las tesis se le añade la diversidad de lugares a los que hacen referencia, mostrando las problemáticas 'locales' y la preocupación de las investigadoras en ser útiles a las poblaciones con las que trabajan. Sus estudios pueden ser una inspiración para nuevos/as jóvenes investigadores/as y, desde luego, enriquecen y contribuyen a descentralizar la geografía feminista a nivel internacional -mayoritariamente anglosajona-. 
Las aproximaciones metodológicas se han hecho más complejas con la profundización en la posicionalidad y la reflexividad en la investigación; también proliferan nuevos métodos, sobre todo en el análisis cualitativo. El uso, hoy escaso, de los Sistemas de Información Geográfica puede aumentar con su aplicación en investigaciones cualitativas dando mayor visibilidad a los resultados obtenidos y atrayendo, quizás, a jóvenes geógrafos/as preparados en esta técnica. También es necesario atraer a hombres jóvenes en la investigación doctoral en geografía y género, cuya presencia actual es muy residual.

El análisis de las tesis defendidas muestra un notable desequilibrio territorial, en consonancia con lo que sucede en otros países y también a nivel internacional (Blidon \& Zaragocín, 2019). Las ausencias en investigación doctoral en geografía y género pueden obedecer a distintas razones: el desconocimiento de la perspectiva de género en geografía, la carencia de formación específica a nivel de $\operatorname{grado}^{6}$ y de máster, ${ }^{7}$ la falta de liderazgo estable en los departamentos/programas de doctorado (mentoras consolidadas en la academia), el positivismo en la geografía más convencional, o la exigencia que este enfoque demanda de una buena disposición a observar nuevos fenómenos y a adoptar nuevas perspectivas. Como expresa Puar (2013), el género, como la clase, la etnicidad, la sexualidad... son lugares de tensión, negociación, resistencia, son procesos en marcha. También pueden concurrir aspectos más profundos derivados de entornos institucionales muy conservadores, y de tradición androcéntrica que provoquen exclusiones conceptuales hacia temas y espacios codificados como femeninos y/o privados, aunque sean relevantes para la vida de las mujeres. Y, por supuesto, considerar los efectos de las políticas neoliberales en la enseñanza de asignaturas críticas como el género, que pueden provocar represión o exilio de aquellas investigadoras que deseen formarse en esta línea.

En esta recopilación hay tesis de tres generaciones de investigadoras. Los trabajos de las generaciones jóvenes han contribuido a ampliar los esfuerzos iniciales y a enriquecer las perspectivas y las temáticas; también han desestabilizado más certezas en la disciplina y han dado espacio a otras disidencias. Detrás de sus investigaciones hay una labor importante de mentorazgo; profesoras e investigadoras comprometidas que las han estimulado e impulsado, no

6 Solamente cinco titulaciones de geografía de las treinta universidades españolas donde esta disciplina se imparte incluyen una asignatura en el plan de estudios que contenga la palabra "género" en el titulo (16,6 \%); y en los casos encontrados es optativa (AGE, 2021).

7 Únicamente cuatro universidades con grados en geografía (26 en total) (15,3\%) cuentan con un máster oficial que incluya la palabra "género" en el titulo (AGE, 2021). 
sin dificultades. El reto que se les plantea a las jóvenes generaciones no es menor. La ausencia de contratos dignos y estables en las universidades públicas orilla a las investigadoras, las sitúa en trabajos múltiples y precarios y amenaza la consolidación y el crecimiento de este campo de la investigación geográfica.

Sin embargo, a pesar de la excelencia de las tesis aquí presentadas, queda todavía mucho camino por recorrer con nuevas preguntas de investigación, nuevos enfoques y nuevas teorías críticas. El último libro publicado por la prestigiosa editorial Routledge (Datta et al., 2020), que compila numerosas investigaciones internacionales sobre geografías de género y feministas, puede servir de inspiración para desarrollar nuevos trabajos de investigación que relacionen de múltiples formas el género, el poder, el lugar y el espacio.

Agradecimientos: Queremos agradecer a las/os dos evaluadoras/es anónimas/os, que han leído el texto y han ayudado a mejorarlo.

Declaración responsable: Las autoras declaran que no existe ningún conflicto de interés con relación a la publicación de este artículo. Las dos autoras han participado en la elaboración del artículo (idea inicial, obtención de datos, revisión bibliográfica) y la redacción de este de forma equitativa. 


\section{Bibliografía}

Asociación de Geografía Española (2021). La geografía en las titulaciones de grado y master en las universidades de España. Retrieved from https://www.age-geografia.es/site/ensenanzauniversitaria-grados/

Añover López, M. (2014). Mujeres empresarias. acciones y estrategias en Aragón desde una mirada feminista. Geographicalia, 65, 5-37. Retrieved from https://dialnet.unirioja.es/servlet/articulo?codigo $=4995592$

Askins, K. (2018). Feminist geographies and participatory action research: co-producing narratives with people and place. Gender, Place and Culture, 25(9), 1277 1294. https://doi.org/10.1080/0966369X.2018.1503159

Baylina, M. (1997). Metodología cualitativa y estudios de geografía y género. Documents d'Anàlisi Geogràfica, $\quad 30, \quad 123-138 . \quad$ Retrieved from https://ddd.uab.cat/pub/dag/02121573n30/02121573n30p123.pdf

Baylina, M., \& Salamaña, I. (2006). El lugar del género en geografía rural. Boletín de la Asociación de Geógrafos Españoles, 41, 99-112. Retrieved from https://bage.agegeografia.es/ojs/index.php/bage/article/view/1993

Blidon, M., \& Zaragocín, S. (2019). Mapping gender and feminist geographies in the global context. Gender, Place and Culture, 26(7-9), 925. https://doi.org/10.1080/0966369X.2019.1636000

Bondi, L. (2005). The place of emotions in research: From partitioning emotion and reason to the emotional dynamics of research relationships. In J. Davidson, L. Bondi \& M. Smith (Eds.), Emotional Geographies (pp. 231-242). Aldershot: Ashgate.

Bosco, F. (2017). Interviews. In D. Richardson et al. (Eds.), The International Encyclopedia of Geography. London: John Wiley \& Sons Ltd.

Burnett, P. (1973). Social change, the status of women and models of city form and development. Antipode: A Radical Journal of Geography, 5(3), 57-62. https://doi.org/10.1111/j.14678330.1973.tb00575.x

Cevedio, M. (2002). Arquitectura y género. Barcelona: Icaria.

Datta, A., Hopkins, P., Johnston, L., Olson, E., \& Silva, J. M. (2020). Routledge Handbook of Gender and Feminist Geographies. Oxon: Routledge. 
Dixon, D., \& Jones, J. P. (2015). Feminist geographies of difference, relation and construction. In S. Aitken \& G. Valentine (Eds.), Approaches to human geography: philosophies, theories, people and practices. (pp. 49-63). London: Sage.

Dowling, R.; Lloyd, K., \& Suchet-Pearson, S. (2016). Qualitative methods I: Enriching the interview. Progress in Human Geography, 679686. https://doi.org/10.1177/0309132515596880

Fielding, N. (2008). Analytic density, postmodernism and applied multi method research. In M. Bergman (Ed.), Advances in mixed methods research (pp. 37-52). London: Sage.

Font-Casaseca, N. (2020). Prácticas cartográficas para una geografía feminista: los mapas como herramientas críticas. Documents d'Anàlisi Geogràfica, 66(3), 565589. https://doi.org/10.5565/rev/dag.594

García Ramón, M.D., \& Nogué, J. (1984). L'evolució dels enfocaments metodològics en la geografia rural catalana. Documents d'Anàlisi Geogràfica, 5, 149-166. Retrieved from https://www.raco.cat/index.php/DocumentsAnalisi/article/view/41335/52169

García Ramón, M. D., \& Monk, J (2007). Gender and geography: world views and practices. Belgeo, 3, 247-259. https://doi.org/10.4000/belgeo.11162

Harding, S. (1987). Is there a feminist method? In S. Harding (Ed.), Feminism and methodology (pp. 9-34). Bloomington: Indiana University Press.

Hayford, A.M. (1974). The geography of women: An historical introduction. Antipode: A Radical Journal of Geography, 6(2), 26-33. https://doi.org/10.1111/j.1467-8330.1974.tb00590.x

Huang S., Monk J., Droogleever Fortuijn J., Garcia Ramon M. D., \& Momsen J. (2017). A continuing agenda for gender: the role of the IGU Commission on Gender and Geography. Gender, Place and Culture, 24(7), 919938. https://doi.org/10.1080/0966369X.2017.1343283

Ibarra, V., \& Escamilla, I. (2016). Presentación. In Ibarra, V. \& Escamilla, I. (Eds.), Geografías feministas de diversas latitudes. Orígenes, desarrollo y temáticas contemporáneas (pp. 1-19). México D.F.: Instituto de Geografía, UNAM.

Kwan, M.P. (2002). Feminist visualization: Re-envisioning GIS as a method in feminist geographic research. Annals of the Association of American Geographers, 92(4), 645661. https://doi.org/10.1111/1467-8306.00309 
Lund, R., Berg, N.G., Jones, M., \& Setten, G. (2019). Feminist geographies in Norway from the turn of the millennium. Gender, Place and Culture, 7-9, 1198-

1214. https://doi.org/10.1080/0966369X.2018.1555151

Massey, D. (1984). Spatial divisions of labour: Social structures and the geography of production. Nueva York: Methuen.

McDowell, L. (2000). Género, identidad y lugar. Madrid: Cátedra.

Monk, J., \& Hanson, S. (1982). On not excluding half of the human in human geography. The Professional Geographer, 34, 11-23. https://doi.org/10.1111/j.0033-0124.1982.00011.x

Monk, J. (1994). Place matters: comparative international perspectives on feminist geographies.

The Professional Geographer, 46(3), 277-288. https://doi.org/10.1111/j.0033$\underline{0124.1994 .00277 . x}$

Moss, P. (1995). Embeddedness in practice, numbers in context: The politics of knowing and doing. The Professional Geographer, 47(1), 442-448. https://doi.org/10.1111/j.0033$\underline{0124.1995 .00442 . x}$

Ortiz, A., \& García Ramón, M. D. (2016). Nuevas tendencias en la geografía de género en España: una revisión de investigaciones publicadas en el último decenio. In M. V. Ibarra García \& I. Escamilla-Herrera (Coords.), Geografías feministas de diversas latitudes. Orígenes, desarrollo y temáticas contemporáneas (pp. 95-122). Ciudad de México: Instituto de Geografía, Universidad Nacional Autónoma de México (UNAM). Retrieved from http://www.publicaciones.igg.unam.mx/index.php/ig/catalog/download/22/22/66$\underline{1 \text { ?inline }=1}$

Ortiz Guitart, A. (2018). Emociones, amor y experiencias migratorias de españoles e italianos calificados en México. Iztapalapa: Revista de Ciencias Sociales y Humanidades, 84 (39), 129156. https://doi.org/10.28928/revistaiztapalapa/842018/atc5/ortizguitarta

Pavlovskaya, M. (2009). Non-quantitative GIS. In M. Cope \& S. Elwood (Eds.), Qualitative GIS: A mixed method approach (pp. 13-39). London: Sage.

Puar, J. (2013). Rethinking homonationalism. International Journal of Middle East Studies, 45(2), 336-339. https://doi.org/10.1017/S002074381300007X

Rose, G. (1993). Feminism and geography: the limits of geographical knowledge. Cambridge: Polity press. 
Sultana, F. (2017). Reflexivity. In D. Richardson et al. (Eds.), The International Encyclopedia of Geography. London: John Wiley \& Sons Ltd.

Tapia González, A. (2018). Mujeres indígenas en defensa de la tierra, Madrid: Ediciones Cátedra.

Taylor, S., \& Bodgan, R. (1992). Introducción a los métodos cualitativos de investigación. Barcelona: Paidós (original 1984).

Vaiou, D. (2018). Intersectionality: old and new endeavours? Gender, Place and Culture, 25(4), 578-584. 


\section{Anexo I. Listado de las tesis doctorales consultadas}

\begin{tabular}{|c|c|c|c|c|}
\hline Nombre y apellidos & Año & Título de la tesis & Programa de doctorado en & Universidad \\
\hline Cànoves Valiente, Gemma & 1990 & Treball invisible, explotació agrària familiar i aportació femenina: el cas de Girona & Geografía & UAB \\
\hline Solsona Pairó, Montserrat & 1991 & Anàlisi demogràfica i territorial de l'activitat femenina. Espanya 1970-1986 & Geografía & UAB \\
\hline Salamaña Serra, Isabel & 1991 & $\begin{array}{c}\text { La dona pagesa, I'oblidada de l'explotació familiar: els casos del Maresme, el } \\
\text { Segrià i el Priorat }\end{array}$ & Geografía & UAB \\
\hline Baylina Ferré, Mireia & 1996 & Trabajo industrial a domicilio, género y contexto regional en la España rural & Geografía & UAB \\
\hline Prats Ferret, Maria & 1997 & Temps i vida quotidiana de les dones de Barcelona & Geografía & UAB \\
\hline Caballé Rivera, Alba & 1998 & Mujer, agroturismo y contexto regional en España & Geografía & UAB \\
\hline Morales Pérez, Soledad & 2002 & $\begin{array}{c}\text { Industria agroalimentaria, género y desarrollo rural. Un análisis comparativo desde } \\
\text { la geografía }\end{array}$ & Geografía & UAB \\
\hline Ortega Lorenzo, Marta & 2002 & $\begin{array}{l}\text { Les telenovel.les catalanes Poble Nou i El Cor de la Ciutat: una anàlisi demogràfica } \\
\text { i des de la perspectiva de gènere }\end{array}$ & Demografía & UAB \\
\hline Cevedio Martín, Mónica & 2002 & Arquitectura y género & Proyectos de arquitectura & UPC \\
\hline Ayllón Trujillo, María Teresa & 2003 & $\begin{array}{l}\text { La intersección familia-identidad-territorio: estrategias familiares en un entorno rural } \\
\text { de fuerte migración: Yucatán a finales del siglo XX }\end{array}$ & $\begin{array}{l}\text { Análisis regional y paisajes } \\
\text { naturales }\end{array}$ & UCM \\
\hline $\begin{array}{l}\text { Paredes della Croce, } \\
\text { Mariana }\end{array}$ & 2003 & $\begin{array}{c}\text { Trayectorias reproductivas, relaciones de género y dinámicas familiares en } \\
\text { Uruguay }\end{array}$ & Demografía & UAB \\
\hline Pedone, Claudia & 2003 & $\begin{array}{c}\text { Tú siempre jalas a los tuyos. Las cadenas y las redes migratorias de las familias } \\
\text { ecuatorianas hacia España }\end{array}$ & Geografía & UAB \\
\hline Veleda da Silva, Susana & 2003 & $\begin{array}{c}\text { Trabajo informal, género y cultura: el comercio callejero e informal en el sur de } \\
\text { Brasil }\end{array}$ & Geografía & UAB \\
\hline Ortiz Guitart, Anna & 2004 & $\begin{array}{c}\text { Gènere, espais públics i construcció del sentit de pertinença a Barcelona (els } \\
\text { barris de Prosperitat, el Verdum i el Raval) }\end{array}$ & Geografía & UAB \\
\hline Edo Benaiges, Maria Josep & 2004 & $\begin{array}{l}\text { Dones i ciutat a la Barcelona del segle XX: una anàlisi geogràfica a través de la } \\
\text { literatura }\end{array}$ & Geografía & UAB \\
\hline Blanco Romero, Asunción & 2005 & $\begin{array}{c}\text { Teletrabajo, género y territorio. Una comparación entre Cataluña, Ardèche y } \\
\text { Québec }\end{array}$ & Geografía & UAB \\
\hline Domínguez Álvarez, Virginia & 2005 & Treball femení en la indústria tèxtil Ilanera de Sabadell durant el segle XX & $\begin{array}{l}\text { Antropología social y } \\
\text { cultural }\end{array}$ & UAB \\
\hline Medina Vargas, Margarita & 2005 & $\begin{array}{l}\text { Historias reproductivas en el contexto de la transición de la fecundidad. Estudio de } \\
\text { la trayectoria conyugal y anticonceptiva de mujeres colombianas }\end{array}$ & Demografía & UAB \\
\hline Sparrer, Marion & 2005 & $\begin{array}{l}\text { El turismo en espacio rural como estrategia de desarrollo. Una comparación a nivel } \\
\text { europeo }\end{array}$ & $\begin{array}{c}\text { Geografía, análisis territorial } \\
\text { y organización del espacio } \\
\text { en Galicia }\end{array}$ & USC \\
\hline Cerarols Ramírez, Rosa & 2008 & $\begin{array}{l}\text { L'imaginari colonial espanyol del Marroc. Geografia, gènere i literatura de viatges } \\
\qquad(1859-1936)\end{array}$ & Geografía & UAB \\
\hline
\end{tabular}




\begin{tabular}{|c|c|c|c|c|}
\hline Nombre y apellidos & Año & Título de la tesis & Programa de doctorado en & Universidad \\
\hline Cucurella Grifé, Ariadna & 2009 & $\begin{array}{l}\text { La perspectiva de gènere en l'ús i el disseny d'espais públics urbans: Mollet del } \\
\qquad \text { Vallès i Manresa }\end{array}$ & Geografía & $U A B$ \\
\hline Díaz Cortés, Fabià & 2009 & $\begin{array}{l}\text { Espai públic, vida quotidiana i identitat de barri a Terrassa: la construcció material i } \\
\text { social de Can Palet i Ca n'Anglada a través d'una geografia de la proximitat }\end{array}$ & Geografía & $U A B$ \\
\hline Vidal Coso, Elena & 2009 & $\begin{array}{c}\text { Activitat i complementarietat sociodemogràfica entre les dones immigrades i les no } \\
\text { immigrades a Espanya }\end{array}$ & Demografía & UAB \\
\hline Agüera Cabo, Mercè & 2010 & $\begin{array}{l}\text { Environmental governance from a gender perspective. Theoretical reflections and } \\
\text { case studies }\end{array}$ & $\begin{array}{l}\text { Ordenación del territorio y } \\
\text { gestión del medio ambiente }\end{array}$ & UdG \\
\hline $\begin{array}{l}\text { Carrasco Tristancho, Rosario } \\
\text { Cinta }\end{array}$ & 2011 & $\begin{array}{c}\text { El proceso migratorio de las mujeres marroquíes: producción, reproducción y } \\
\text { transformación de las identidades de género y culturales }\end{array}$ & $\begin{array}{l}\text { Género, identidad y } \\
\text { ciudadanía }\end{array}$ & UHU \\
\hline Pujol Estragués, Hermínia & 2011 & $\begin{array}{c}\text { La presència de les dones a la geografia acadèmica: de la geògrafa absent a la } \\
\text { geògrafa desapareguda }\end{array}$ & Geografía & UAB \\
\hline Ferrer Serret, Laia & 2012 & $\begin{array}{l}\text { Lògiques socials i decisions individuals de la interrupció voluntària de l'embaràs: } \\
\text { Espanya a través d'una perspectiva comparada }\end{array}$ & Demografía & $U A B$ \\
\hline Pose García, Mariña & 2012 & $\begin{array}{c}\text { Género y nuevas tecnologías de la información y la comunicación. Fundamentos } \\
\text { teóricos y estudio de casos }\end{array}$ & $\begin{array}{l}\text { Geografía, análisis territorial } \\
\text { y organización del espacio } \\
\text { en Galicia }\end{array}$ & USC \\
\hline $\begin{array}{l}\text { Coelho Rocha, Irlandia } \\
\text { Maria Serra Negra }\end{array}$ & 2013 & A mulher universitaria e sua relaçao com a proprio envelhecimiento & $\begin{array}{l}\text { Geografía, planificación } \\
\text { territorial y gestión ambiental }\end{array}$ & UB \\
\hline Chager Navarro, Sonia & 2014 & $\begin{array}{l}\text { Tying the knot and kissing childhood goodbye? Early marriage in educationally } \\
\text { expanding societies }\end{array}$ & Demografía & $U A B$ \\
\hline Añover López, María & 2014 & Mujeres empresarias. Acciones y estrategias en Aragón & $\begin{array}{l}\text { Relaciones de género y } \\
\text { estudios feministas }\end{array}$ & UNIZAR \\
\hline De Reymaeker, Brice & 2014 & $\begin{array}{l}\text { La cooperación al desarrollo desde la perspectiva del espacio relacional y } \\
\text { construido: Encuentros, desencuentros y traducciones en los proyectos catalanes y } \\
\text { andaluces de desarrollo y género en el norte de Marruecos }\end{array}$ & Geografía & $U A B$ \\
\hline Cioccoletto, Adriana & 2014 & $\begin{array}{c}\text { Urbanismo para la vida cotidiana. Herramientas de análisis y evaluación urbana a } \\
\text { escala de barrio desde la perspectiva de género }\end{array}$ & $\begin{array}{l}\text { Gestión y valoración urbana } \\
\text { y arquitectónica }\end{array}$ & UPC \\
\hline $\begin{array}{l}\text { Mojica Segovia, Ana } \\
\text { Carolina }\end{array}$ & 2014 & $\begin{array}{c}\text { Hábitat urbano y vida cotidiana: una mirada de género a la organización espacio- } \\
\text { temporal de las actividades en León, México }\end{array}$ & $\begin{array}{l}\text { Geografía y desarrollo: } \\
\text { territorio, sociedad y turismo }\end{array}$ & UCM \\
\hline Pallarès Blanch, Marła & 2014 & $\begin{array}{c}\text { Estratègies de desenvolupament local rural, gènere i processos innovadors en la } \\
\text { nova ruralitat: I'aportació de les dones al desenvolupament, la innovació i la } \\
\text { governança territorial a l'Alt Pirineu i Aran (Catalunya) }\end{array}$ & Geografía & UAB \\
\hline Rodó de Zárate, Maria & 2014 & $\begin{array}{c}\text { Geografies de la interseccionalitat: I'accés de la joventut a l'espai públic de } \\
\text { Manresa }\end{array}$ & Geografía & $U A B$ \\
\hline
\end{tabular}




\begin{tabular}{|c|c|c|c|c|}
\hline Nombre y apellidos & Año & Título de la tesis & Programa de doctorado en & Universidad \\
\hline $\begin{array}{l}\text { Pérez Rincón Fernández, } \\
\text { María del Socorro }\end{array}$ & 2014 & $\begin{array}{l}\text { Voces femeninas en barrios en transformación: desorden aparente y realidades } \\
\text { paralelas }\end{array}$ & $\begin{array}{l}\text { Geografía, planificación } \\
\text { territorial y gestión ambiental }\end{array}$ & UB \\
\hline Castela Egido, Miguel Ángel & 2015 & $\begin{array}{c}\text { Caminant de la mà dels infants. Una anàlisi des de la Geografia de la mobilitat } \\
\text { infantil a Granollers (Catalunya) }\end{array}$ & Geografía & UAB \\
\hline Solana Villanueva, Nélyda & 2015 & $\begin{array}{l}\text { Mujeres jóvenes de la zona del Pacífico y el golfo de México vivencias, prácticas y } \\
\text { espacios cotidianos }\end{array}$ & Geografía & UAB \\
\hline Hervás Moreno, Inmaculada & 2016 & $\begin{array}{c}\text { El papel de las mujeres emprendedoras en la implantación y desarrollo del turismo } \\
\text { rural en el Pirineo Aragonés (1990-2013) }\end{array}$ & Geografía Humana & UNIZAR \\
\hline $\begin{array}{l}\text { Cedro Barrionuevo, María } \\
\text { Victoria }\end{array}$ & 2016 & $\begin{array}{l}\text { La participación ciudadana en la construcción urbana de la Vila de Santa Luzia } \\
\text { (Recife, Brasil) un diálogo desde el género, la identidad y la política }\end{array}$ & Geografía & UAB \\
\hline $\begin{array}{l}\text { Braga de Melo Fadigas, } \\
\text { Amanda }\end{array}$ & 2017 & $\begin{array}{c}\text { The consequences of the prestige oil disaster for the galician shellfisherwomen and } \\
\text { their role in the regeneration of the shellfishing zones }\end{array}$ & $\begin{array}{l}\text { Ciencias experimentales y } \\
\text { sostenibilidad }\end{array}$ & UdG \\
\hline Delicado Moratalla, Lydia & 2017 & $\begin{array}{l}\text { Desde la esclavitud de mujeres negro africanas a la prostitución nigeriana en } \\
\text { Alicante. Una geografía feminista (ss. XVI-XXI) }\end{array}$ & $\begin{array}{l}\text { Estudios interdisciplinares } \\
\text { de Género }\end{array}$ & UA \\
\hline $\begin{array}{l}\text { Nomdedeu Calvente, María } \\
\text { Zoraida }\end{array}$ & 2017 & $\begin{array}{l}\text { La construcción de la identidad de las mujeres a través de la imagen de los } \\
\text { espacios interiores }\end{array}$ & $\begin{array}{c}\text { Estudios e investigación } \\
\text { sobre las mujeres, feministas } \\
\text { y de género }\end{array}$ & UJI \\
\hline $\begin{array}{l}\text { Moreno Alarcón, Daniela } \\
\text { Francisca }\end{array}$ & 2017 & $\begin{array}{l}\text { Turismo y Género: un enfoque esencial en un contexto de desarrollo sostenible y } \\
\text { responsable del turismo }\end{array}$ & $\begin{array}{l}\text { Perspectiva feminista como } \\
\text { teoría crítica }\end{array}$ & UCM \\
\hline Domínguez Rodríguez, Antía & 2018 & Salud, género y educación en la transición a la jubilación & Demografía & UAB \\
\hline Dorrego Carlón, Ana & 2018 & $\begin{array}{c}\text { Las mujeres en los sistemas de producción bajo principios agroecológicos en } \\
\text { Bolivia }\end{array}$ & Geografía & UCM \\
\hline García Saladrigas, Núria & 2018 & El uso del tiempo de los hogares reconstituidos y monoparentales & Demografía & UAB \\
\hline Gómez Casillas, Amalia & 2018 & $\begin{array}{c}\text { Violencia de género y prácticas tradicionales perjudiciales: una contribución al } \\
\text { debate metodológico para su medición en Europa }\end{array}$ & Demografía & UAB \\
\hline Mecca, Margot & 2018 & $\begin{array}{c}\text { Descubriendo el ocio nocturno urbano. Primeras experiencias entre adolescentes en } \\
\text { Barcelona }\end{array}$ & Geografía & $U A B$ \\
\hline $\begin{array}{l}\text { Pinheiro Machado Brochner, } \\
\text { Gabriela }\end{array}$ & 2018 & $\begin{array}{c}\text { Articulaciones feministas y procesos de reescalado en América Latina un estudio del } \\
\text { trabajo en red del movimiento de mujeres campesinas (MMC) de Brasil }\end{array}$ & $\begin{array}{c}\text { Ciencias Políticas y de la } \\
\text { administración y relaciones } \\
\text { internacionales }\end{array}$ & UCM \\
\hline $\begin{array}{l}\text { Ruiz Vallejo, Herney } \\
\text { Fernando }\end{array}$ & 2018 & $\begin{array}{c}\text { La separación conyugal en Colombia, 1951-2015: geografías y biografías en clave } \\
\text { de género }\end{array}$ & Demografía & $U A B$ \\
\hline Salvatori, Sara & 2018 & $\begin{array}{l}\text { La migración invisibilizada de mujeres cualificadas de Monterrey (México) a } \\
\text { Houston (Estados Unidos). Una interpretación desde el enfoque interseccional }\end{array}$ & Estudios migratorios & UPO \\
\hline $\begin{array}{l}\text { Tapia González, Georgina } \\
\text { Aimé }\end{array}$ & 2018 & Mujeres indígenas y medio ambiente. Una mirada desde la filosofía de la cultura & $\begin{array}{l}\text { Filosofía de la cultura, de la } \\
\text { ciencia y de la sociedad }\end{array}$ & UVA \\
\hline
\end{tabular}




\begin{tabular}{|c|c|c|c|c|}
\hline Nombre y apellidos & Año & Título de la tesis & Programa de doctorado en & Universidad \\
\hline Pallarés Ameneiro, Laura & 2019 & Prostitución femenina en México DF: estudio de casos & $\begin{array}{l}\text { Historia, geografía e historia } \\
\text { del arte }\end{array}$ & USC \\
\hline Serra Salvi, Anna & 2019 & $\begin{array}{c}\text { Vida quotidiana, espai públic i construcció de sentit de pertinença a Girona. Una } \\
\text { anàlisi intergeneracional, interseccional i de gènere }\end{array}$ & Medio ambiente & UdG \\
\hline Veloz Jaramillo, Gloria & 2019 & $\begin{array}{l}\text { Modelo de asociatividad para el desarrollo sostenible de territorios indígenas de la } \\
\text { amazonía ecuatoriana. El caso del Pueblo Kichwa Rukullakta }\end{array}$ & Geografía & UAB \\
\hline $\begin{array}{l}\text { Cuevas Ramírez, Lina } \\
\text { Eugenia }\end{array}$ & 2020 & La entrada en unión de las mujeres en México & Demografía & UAB \\
\hline Hajjaj, Maysa A. & 2020 & Wellbeing perspective and the gender question in Palestine: a critical analysis & $\begin{array}{l}\text { Feminismo y estudios de } \\
\text { género }\end{array}$ & UCM \\
\hline Maciejewska, Monika & 2020 & $\begin{array}{c}\text { Diferencias de género en el uso de los modos de transporte: casos de estudio de } \\
\text { Barcelona y Varsovia }\end{array}$ & Geografía & UAB \\
\hline Méndez Caro, Leyla & 2021 & $\begin{array}{c}\text { Corpolugaridades y contrapaisajes de la nación. Mujeres migrantes sudamericanas } \\
\text { y las disputas por el estar en campamentos de Antofagasta, Chile }\end{array}$ & $\begin{array}{l}\text { Interuniversitario en estudios } \\
\text { de mujeres y género }\end{array}$ & UAB \\
\hline Saldaña Blasco, Dafne & 2021 & $\begin{array}{c}\text { El espacio como agente coeducador. Participación y transformación feminista de } \\
\text { patios escolares en Santa Coloma de Gramenet }\end{array}$ & $\begin{array}{l}\text { Interuniversitario en estudios } \\
\text { de mujeres y género }\end{array}$ & UAB \\
\hline Valdivia Gutiérrez, Blanca & 2021 & La ciudad cuidadora. Calidad de vida urbana desde una perspectiva feminista & $\begin{array}{l}\text { Gestión y valoración urbana } \\
\text { y arquitectónica }\end{array}$ & UPC \\
\hline
\end{tabular}

Fuente: elaboración propia a partir de los datos obtenidos en TESEO 